\title{
Joining host/guest with contrary affinity at the nanoscale by chemical bonds or non-covalent interactions with organic media under diffusion: control of embedded versus exposed magnetite dispersions.
}

Susanna Jansat ( $\square$ sjansats@gmail.com )

Uol https://orcid.org/0000-0002-6577-5945

Mercè Moncusí

Servei de Recursos Cientifics i Tècnics (SRCiT) de la Universitat Rovira i Virgili

\section{Research Article}

Keywords: joining host/guest of opposite polarity, morphology control of supported solids, diffusion assisted protocol, organic media

Posted Date: July 15th, 2021

DOI: https://doi.org/10.21203/rs.3.rs-722270/v1

License: (1) This work is licensed under a Creative Commons Attribution 4.0 International License. Read Full License 


\section{Abstract}

Emulating natural dynamism distributing earth minerals using diffusion and gravity, herein it is reported a strategy to unite nanostructured materials of similar size but intrinsic physical repellence, magnetite guest bestowed with $\mathrm{C}_{18}$ alkyl chain ligands and highly hydrophilic ammonium dawsonite $\mathrm{NH}_{4} \mathrm{Al}(\mathrm{OH})_{2} \mathrm{CO}_{3}$ host, based in electromagnetic and chemical forces. Notwithstanding augmented polarity of nanostructured surface's carrier, has been used as fine-tuning tool in conjunction with continuum, for triggering a disseminated array of specific interactions covering entire carrier $\mathrm{NH}_{4}{ }^{+}$-RDW-NP periphery. Strong interactions heighten enthalpic contributions balancing unfavourable entropic penalty. Shelter adsorbs diffused guest like conventional $\mathrm{Fe}_{3} \mathrm{O}_{4}-\mathrm{NP}$ dispersions but additionally, whether restricts void's access or, sinters carrier enabling isolation of a second morphology where magnetite is quantitatively embedded into cavities left between agglomerates. Reported deposition protocol extends sort of practical interactions beyond the known dipole-dipole derived ones, to ion-p and truly chemical coordination bonds, strengthening wetting interfaces that define noticeable g- $\mathrm{Al}_{2} \mathrm{O}_{3}$ crystalline domains at minor temperatures. Manuscript illustrates how certain organic media may assist to reliable guest depositions in, hydrotalcite to alumina carriers within controlled morphology, at the same weight level than common procedures reported for more akin host/guest. Interestingly, protocol enables practical $\mathrm{S}_{\mathrm{BET}}$ measurements for solids with significative contributions of interparticle porosity. Detrimental effects are also addressed.

\section{Introduction}

Diffusion processes are ubiquitous in nature and their presence is vital for life preservation. Humans might reproduce them entrapped in a flask, under a richer variety of interactions, to purposely accomplish a greener route. Mild diffusion conditions present the advantage to safely manipulate very sensitive entities, extending then, surface engineering strategies to deposit IONSP, onto carriers unprotected towards mechanical harassment. Additionally of not being an expensive source, IONSP have generated a prolific number of valuable applications. ${ }^{1}$ For instance, metal oxides spinel's show good performances in processes, where redox properties are strategic like $d e \mathrm{~N}_{2} \mathrm{O}$ abatement, ${ }^{2} \mathrm{OER}$ and ORR reactions. ${ }^{3}$ Besides, presence of reducible surfaces crucially assists in mobility and release of oxygen expediting advance of reactions. In line to it, vital interest of $\mathrm{N}_{2} \mathrm{O}$ and $\mathrm{NOx}$ decompositions, has launched a plethora of distinctive materials like active catalysts comprising hexaluminosilicates, ${ }^{4}$ metal oxide spinels, ${ }^{5}$ ironzeolites $\left(\right.$ EnviNOX $\left.^{\mathrm{R}}\right){ }^{6}$ perovskytes, ${ }^{7}$ hydrotalcites, ${ }^{8}$ including a big group of $\mathrm{M}(0)$-NP catalyst supported in oxides $\left(\mathrm{Al}_{2} \mathrm{O}_{3},{ }^{9} \mathrm{SiO}_{2} / \mathrm{SBA} 15^{10}\right)$ and, carbonaceous materials (carbon nanotubes with and without metal doping ${ }^{11}$ and, mesoporous carbon $\mathrm{CMK}-3^{12}$ ), among others.

Great variety of successful catalysts gives us the idea to develop a protocol, for supporting common metallic nanoparticles (MNP) sterically protected by long alkyl chains, onto any inorganic carrier, without omitting more defiant polar ones like ammonium dawsonite nanoparticles used here $\left(\mathrm{NH}_{4}{ }^{+}-\mathrm{RDW}-\mathrm{NP}\right)$. 
Hydrophobic guest have been modelled with $\mathrm{Fe}_{3} \mathrm{O}_{4}-\mathrm{NP}$, but might represent any metallic core surrounded by long chain stabilizers, as for example more condensed M(0)-NP entities.

Key point for challenging assembly is the role accounted by chosen continuum, developing chemical coordinative bonds and, p-ion contacts, linking media and host surface. Success relies into compulsory cooperation, along ternary [host-media-guest] system, stablishing whether strong p-ion non-covalent interactions heightened in co-existence of quadrupolar moments or, real coordinative bonds, in inner side of wetting interface where distinctive polarity with guest has been greatly lessened. Occurrence enables connecting IONSP through metastable molecular interactions in exposed adsorbate covering. Judicious selection of organic media and finite size of both partners, allows for exquisite fine-tuning of ultimate solid morphology, entirely avoiding drying phenomena, ${ }^{13}$ and guest's expelling, while directing intimate liquid microstructure of emulsion and, intermolecular associations happening at the nanoscale where quantum effects dominate. ${ }^{14}$

Although solvent's polarity has been convenient to drive the selective guest's storage over meso- and microporosity, ${ }^{15}$ but also in outward surface via anti-solvent induced adsorption, ${ }^{16}$ straight-forward carrier's synthesis around metallic particles keeps being the most discriminatory way to isolate filled mesopores. ${ }^{17}$ To the best of our knowledge, use of diffusion techniques harmonizing polar host, organic media, non-polar guest, corresponding interactions and, final solid morphology, is original to join phases with extreme repellence and additionally, compatible with the employ of templates whose original structure could be damaged under harder conditions (acidity, sonication, vortexing or, high temperature). In relation, organic media has been effective to control deposition of alike materials as CoO-NP ${ }^{18}$ in PSDVB, functionalization of porous solids with precise nanoscale resolution using individual localized wetting states ${ }^{19}$ and, beneficial to impregnate metallic salts in alumina extrudates ${ }^{15}$ using glycerol but, when physical affinity is not met at any level, alternative interactions as ones presented here are necessary.

For instance, chemical reaction of impregnated complexes with host surface is already reported as effective solution ${ }^{20}$ and, in direct relation with our proposal, $\mathrm{CHCl}_{3}$ and $\mathrm{CH}_{2} \mathrm{Cl}_{2}$ have been used to generate an evenly distribution of dipoles in polar host ${ }^{21}$ (zeolites, hydroxyapatite $\mathrm{Ca}_{10}\left(\mathrm{PO}_{4}\right)_{6}(\mathrm{OH})_{2}$, a$\mathrm{Fe}_{2} \mathrm{O}_{3}, \mathrm{TiO}_{2}, \mathrm{ZnO}$, and $\mathrm{SiO}_{2}$ ), facilitating interaction with $\mathrm{Au}(0)$-NP under stirring. Still, mentioned media will harm irreversibly used ammonium dawsonite $\mathrm{NH}_{4}{ }^{+}$-DW-NP carrier.

Herein, we demonstrate that stablishing stronger chemical bonds into solvent's adsorbate layer, creates sturdier interfacial energies, implementing hardest fixations under any condition and, definite cooperation upgrade the whole set of forces, towards defiant union despite high entropic penalisation softened by released surface bound water in pristine $\mathrm{NH}_{4}{ }^{+}$-DW-NP. Proven attainment of supported materials, launch diffusion as consistent tool to be used, within efficient ternary [host-media-guest] systems, in base of challenging affinities and predicted interactions, widening the list of available means and solid morphologies, to be isolated stabilizing MNP in hydrotalcite to alumina precursors. ${ }^{22}$ Nevertheless, 
protocol might be seen as universal deposition method mediated by diffusion unless proper solvent selection available. Moreover, presented diffusion procedure might gain consideration to model confinement's dynamism of less polar molecular species like methane, organic matter and, $\mathrm{CO}_{2}$ onto mesoporous minerals on earth, enriching knowledge on physical chemistry, geochemistry and pedogenesis areas.

\section{Results And Discussion}

\section{Synthesis and selection of starting materials}

Manuscript reports a two-step procedure for the deposition of metastable and preformed hydrophobic 3$10 \mathrm{~nm}-\mathrm{M}_{\mathrm{x}} \mathrm{O}_{\mathrm{y}}-\mathrm{NP}$ (MNP guest), over a highly hydrophilic reconstructed ammonium dawsonite carrier conformed by a fine distribution of reformed ammonium dawsonite $\mathrm{NH}_{4}{ }^{+}-\mathrm{RDW}-\mathrm{NP}$ around 15 $\mathrm{nm}\left(\mathrm{NH}_{4} \mathrm{AlCO}_{3}(\mathrm{OH})_{2}\right)$.

Host presents a bimodal distribution of mesoporous 4-11 nm voids and more distorted structure than dawsonite $\mathrm{NaAlCO}_{3}(\mathrm{OH})_{2}$ mineral, being isomorphic to $\mathrm{KAICO}_{3}(\mathrm{OH})_{2}$ when hydrogens are not considered (radii: $\mathrm{K}^{+}=133$ and $\mathrm{NH}_{4}{ }^{+}=143 \mathrm{pm}, \mathrm{SI}$ ). Proven memory effect accounted between derived dawsonite materials during synthetic conditions, permits the recovery of exact as-made $\mathrm{NH}_{4}{ }^{+}-\mathrm{DW}^{-} \mathrm{NP}^{23}$ structure in reformed $\mathrm{NH}_{4}$-RDW-NP solids. In fact, latter is isolated after carbonation in aqueous $\left(\mathrm{NH}_{4}\right)_{2} \mathrm{CO}_{3}$ at $323 \mathrm{~K}$ of amorphous alumina calcined from as-made $\mathrm{NH}_{4}{ }^{+}$-DW-NP, synthetized using in-line-dispersionprecipitation ILDP method (Equation Figure 1). PXRD and TEM raised average size for $\mathrm{NH}_{4}{ }^{+}$-DWNP distribution around 6 and $10 \mathrm{~nm},{ }^{23}$ respectively. Lessened size deviations within lower crystallinity are affordable, via continuous precipitation protocols realized, under 1 bar of pressure and 18 seconds of residence time. ${ }^{24}$ In contrast, reformed solids over longer periods of reconstruction and, consecutive thermal treatments, increase absolute dimensions and, might enhance rigidity of crystalline networks, in function of the temperature used during calcination step (Equation Figure 1).

Besides, hydrophobic $10 \mathrm{~nm}-\mathrm{Fe}_{3} \mathrm{O}_{4}$-NP guests, capped by oleyl amine (OAm) and oleic acid (OA), were isolated by thermal $\mathrm{Fe}(\mathrm{acac})_{3}$ decomposition, in a purposely wide range size's distribution with the aim of distinguishing, if present, size-selective tendencies into the challenging union. More optimal $\mathrm{Fe}_{3} \mathrm{O}_{4}-\mathrm{NP}$ dispersions might be isolated using higher amounts of exact surfactants under similar experimental conditions ${ }^{25}$ or, in presence of seeds. ${ }^{26}$ Magnetite $10 \mathrm{~nm}-\mathrm{Fe}_{3} \mathrm{O}_{4}$-NP used, denoted as $\mathrm{Fe}_{3} \mathrm{O}_{4}(10) / \mathrm{OA} / \mathrm{OAm}$ when emphasizing organic contents, delineate a non-gaussian skewed distribution of diameters. Sparsity is formally defined like $10.03+4.35 /-0.85 \mathrm{~nm}$ ranging from 5.60 to $10.88 \mathrm{~nm}$ (Figure $1 \mathrm{~A}$ ). Smaller 5.60$6.99 \mathrm{~nm}$ dimensions constitute the $4.92 \%$ of the total sample (427 NP count, SI5A). TEM pictures display the usual faceted nature enclosed in an apparent spherical shape and, percentage of ligands in primary and secondary shelters have been quantified by TGA, following the already reported guidelines: Losses around $250^{\circ} \mathrm{C}(17.23 \%)$ and $420^{\circ} \mathrm{C}(8.57 \%)$, attributed to less interacting added peripheral layers and, 
more internal glossed by cohesive forces ${ }^{27}$ leading to the stable and superlative non-polar nature, indebted to the presence of dense number of alkyl chains interacting by Van deer Waals forces on the emulsion (Figure SI2). Sensitive towards oxidation, dispersions of $3 \mathrm{~nm}$-CoO-NP were done to reinforce and, complement results generated by wide range of diameters present in former IONSP sample. Coderived counterparts, protected within an important shield of OA ligands conferring equally a firm hydrophobic character, were isolated following synthetic method based in the removal of $\mathrm{CO}$ ligands by radical TEMPO. ${ }^{18}$ Gratifyingly, synthetized $10 \mathrm{~nm}-\mathrm{Fe}_{3} \mathrm{O}_{4}$-NP nanoparticles form dispersions in low permittivity media stable for more than 3 months (Toluene and Hexane, Table SI1) as well as, smaller counterparts in $o-D C B / T H F$ media mixes (non-measured times).

Additional interest in using such specific host, is the proven generation of an ultra-pure g- $-\mathrm{Al}_{2} \mathrm{O}_{3}$ phase (DWC) with higher porosity, thermal stability and, surface area after anaerobic calcination expelling $\mathrm{CO}_{2}$ and $\mathrm{NH}_{3} \cdot{ }^{23,28}$ Conveniently, thermal step in supported solids transforms host in amorphous alumina (DWC) and, dense shield of organic stabilizers in MNP onto a thin carbonaceous frontier, locking stronger stabilized metallic contributions in $\mathrm{M}_{\mathrm{x}} \mathrm{O}_{\mathrm{y}} / \mathrm{C} @ D W C$ solids (Equation Figure 1).

Point zero charge (PZC) of $\mathrm{NH}_{4}{ }^{+}$-RDW-NP surface corresponds to a periphery free of ionized functions, defined equally as the $\mathrm{pH}$ where net charge of total particle surface is zero. Such point has an extreme importance in adsorption capacity and colloidal flocculation processes, though herein has been slightly fine-tuned with media to control ultimate deposition. Since, $\mathrm{pH}$ of surface couldn't be presumed equivalent and constant during diffusion, either due to significative polarity alterations intrinsic of the heterogeneous emulsion or, potentially accessible ionicity of external carbonate functions in protic media on presence of exogenous ions, and considering the intricate nature that might sustain ILPD dawsonite solids (crucial aspect treated in last section): Resolution it is difficult, but controversially accessible, analysing $\mathrm{NH}_{4}{ }^{+}$-RDW-NP features that challenge at the uppermost the meant union. Such properties are: Innately strained host net accentuating the exposition of peripheral functions (big ammonium cation), strong interfacial magnetic dipole interaction over large uncovered surface, putative high degree of interparticle porosity revealed for $\mathrm{NH}_{4}{ }^{+}$-DW-NP at the finite size, ${ }^{23}$ enhanced acidity and peripheral chemical polarity, in combination with Solvent Physical Parameters (SPhP) ${ }^{29}$ and mature interactions. Agglutination of enumerated factors has unveiled the functioning mechanism in every tested continuum.

Pouring $\mathrm{NH}_{4}{ }^{+}$-RDW-NP host into certain organic solvents lessen weighty intraparticle porosity's contribution mainly associated to the nanostructured state, stablishing a novel periphery softened after solvation, without altering any chemical function by interfacial reactivity, unless hydrogen bonds or, ion pairing equilibria with ionizable short chain alcohols like surface carbonates reducing observed x potential (zeta potential). Likewise, protonation of host functions might decrease $\mathrm{pH}$ in surface bellow isoelectronic point originating electrostatic depositions, in simultaneity with charge transfer events when $\mathrm{pH}$ of emulsion is found amid isoelectronic point of guest and host, ${ }^{30}$ a nonneglectable option in described tests. Physisorption is materialized by non-covalent interactions like 
assumed hitherto step before chemisorption, further robustized implementing chemical linkages. Herein, host covering shelter might be seen as a covalent modification, but with an intrinsic metastability that prevails up to anaerobic calcination. Ubiquitous decoration of strong permanent dipoles, Brönsted and Lewis acid/basic sites and plausible defects, justify why diffusion protocol does not require to adjust $\mathrm{pH}$ or temperatures, because solvation of carrier particles is effective by itself. Small size of host and guest overwhelms mass attraction in front of electromagnetic forces (EM), delineating observed wettability (SPhS) and, ultimate chemisorption whether via cooperation of chemical coordinative bond, dipolar interaction, hydrogen bond or, p-ion interaction. Encompassing all details together, it is inevitable to prospect a leading role of $\mathrm{NH}_{4}$-RDW-NP surface, organizing throughout surrounding solvent molecules, settling stated links with labile carrier functions, therefore, fiercely driving microstructure of the emulsion, crucial mean to settle wide interface thickness in less polar pores and peripheral surfaces. Consequently, scenario reduces drastically dimensions of kinetic radii eligible of being introduced in inner voids.

Although chemical structure of involved adsorbates might alleviate imposed restriction, it is an imperative regulation due the extreme discrepancy of physical character in starting host/guest materials.

Knowing that intermolecular interactions between heterogeneous dispersals occur at the nanoscale level, we sought that a fine dispersion of highly polar $\mathrm{NH}_{4}{ }^{+}$- $\mathrm{RDW}-\mathrm{NP}$ would be the right platform to test the challenging deposition, using several sizes of hydrophobic guest in a variable set of continuums (MxOy$N P, M=F e, x=3, y=4,10 \mathrm{~nm} ; M=C o, x=y=1,3 \mathrm{~nm}$ ). Decisively, experimental results presented here, might stablish fundamentals towards the controlled joining of non-affine surfaces, mediated by solvent molecules bridging and accommodating opposite polarities. Indeed, continuum's microstructure reflects distinctive solvation of solid solutes present. Described heterogeneousness, though being apparently hidden to our eyes, has been specifically demonstrated at the nanometre-scale using formamide and dimethylformamide probes in mixtures of solvents. ${ }^{14}$ Still, adsorption capacity of created outward adsorbate's layer enclosing $\mathrm{NH}_{4}{ }^{+}$-RDW-NP, depends on its intrinsic ability for conducting polar $\mathrm{NH}_{4}{ }^{+}-\mathrm{RDW}$ NP nature (polarizability), via magnetic $B$ and electric $E$ fields modulated by quantum effects.

$\mathrm{NH}_{4}{ }^{+}$-RDW-NP host is a dawsonite recrystallized, from a treated alumina in $\left(\mathrm{NH}_{4}\right)_{2} \mathrm{CO}_{3}$ solution, recovering arrangement of pure ammonium dawsonite phase (memory effect). Specifically, used $\mathrm{NH}_{4}{ }^{+}-$ RDW-NP carrier an corresponding calcined alumina solid, in no presence of guest, show corresponding textural properties to ones already reported ${ }^{28}$ from analogous ILDP samples (DW solids: As-made $<6 \mathrm{~nm}$ $\mathrm{NH}_{4}{ }^{+}$-DW-NP/ $<50 \mathrm{~nm}-\mathrm{NH}_{4}{ }^{+}$-RDW-NP from g- $\mathrm{Al}_{2} \mathrm{O}_{3}$ calcined at different temperatures ${ }^{23} /$ used $<15 \mathrm{~nm}$ $\mathrm{NH}_{4}{ }^{+}$-RDW-NP: $V_{\text {pore }}=1.6 / 1.2-0.7 / 1.32 \mathrm{~cm}^{3} \mathrm{~g}^{-1} ; \mathrm{S}_{\mathrm{BET}}=773 / 1046-300 / 586 \mathrm{~m}^{2} \mathrm{~g}^{-1} ;$ DWC or $\mathrm{Al}_{2} \mathrm{O}_{3}$ solids:

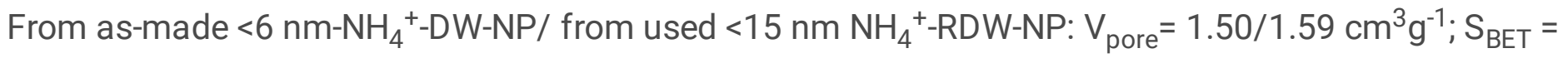
$\left.500 / 491 \mathrm{~m}^{2} \mathrm{~g}^{-1}\right)$.

However, retro-topotactic transformation including consecutive thermal steps in experimental sequence carried out (as-made $<6 \mathrm{~nm} \mathrm{NH}_{4}{ }^{+}$-DW-NP (ILDP) ${ }^{\circledR} 5 \mathrm{~nm}$-DWC-NP (calcination) ${ }^{\circledR}<15 \mathrm{~nm} \mathrm{NH}_{4}{ }^{+}$-RWC-NP (aqueous carbonation/novel protocol) $\mathrm{Fe}_{3} \mathrm{O}_{4} / \mathrm{C} @ D W C-\mathrm{NP}$ (calcination), Equation Figure 1), originates 
concrete alterations in chemical composition, assembly of phases present and, mechanical stability, henceforward creating the peripheral affinity to govern microstructure of emulsion. BJH distribution, in used $\mathrm{NH}_{4}{ }^{+}$-RDW-NP and supported solids, reveals preservation of uniform $11 \mathrm{~nm}$ mesopore pattern and type IV adsorption isotherms with $\mathrm{H} 1$ hysteresis of as-made materials but, consecutive thermal treatments broaden diameters of minor pores, in feasible founding of more rigid nets. Accordingly, pristine RDW carrier and calcined samples supporting metallic populations, show bimodal distributions for mesopores centred about 4 and $11 \mathrm{~nm}$ (Figure 1B when toluene is used as diffusion media).

Enumerated features are found in entire agreement with secondary 2-5 $\mathrm{nm}^{31}$ network, bimodal meso- and macropores distributions attributed to the removal of gaseous effluents during $\mathrm{NH}_{4}{ }^{+}-\mathrm{DW}^{32}$ nanorods decomposition, as well as, intracrystalline porosity, ${ }^{33}$ previously remarked by other authors in analogous solids.

The scope of present manuscript is fourfold: 1. Presentation of unprecedent diffusion route, joining nonaffine guests and host by real chemical bonds and non-covalent interactions within organic media. 2 . Absolute control engagement of final solid morphology like extra advantage, adding high value in novel procedure versus commonly used methods. 3. Straight-forward application of diffusion tests results, to predict qualitatively arrangement of expended carrier, extensive to be applied onto alternative dawsonite ILPD materials. 4. Critical presentation, as derived application for novel route procedure, of how to get realistic and practical $\mathrm{S}_{\mathrm{BET}}$ areas, in solids bearing significative contributions of interparticle porosity in solid state.

\section{Supported mesoporous solids furnished by diffusion protocol}

Decreasing physical affinity of partners to be joined requires of new solutions, to accomplish same aim than reported polar surfaces $\mathrm{CH}_{2-n} \mathrm{Cl}_{2+n}$ covering, as one presented here, adding alternative non-harmful but stronger linkages, when halogenated continuums couldn't be used, owing to stability of starting materials. Crucial attraction with hydrophobic guest, is common in all cases via dipole derived noncovalent interactions (dipole-charge, dipole-dipole, and dipole-induced dipole), as transitory link up to calcination step. Hydrophobic interactions in latter set couldn't be disused if neutral PZC host's surfaces are present.

Homogeneous solvation shelters are ensued because non-competitive interaction amid solvent and MNP adsorbates with $\mathrm{NH}_{4}{ }^{+}$-RDW-NP surface. In fact, MxOy-NP deposition uniquely happens after the completion of media's adsorbates shell. High entropic penalty incurred into emulsion's microstructure, it is compensated with entropy factor coming from the release of adsorbed bound water molecules into pristine host and, huge enthalpic gain generated by formed bonds and interactions, mostly between solid host particles and media. Diffusion of magnetic $10 \mathrm{~nm}-\mathrm{Fe}_{3} \mathrm{O}_{4}-\mathrm{NP}$ nanoparticles, towards pores and surface of amorphous $\mathrm{NH}_{4}{ }^{+}$-RDW-NP, were carried out at room temperature, in several organic media featuring non-comparable SPhP (e, Solvent Dipolarity -SdP-, Solvent Polarizability -SPP-, HP- Hildebrand-, acidity and coordination ability). Singular parameters are crucial, in combination with chemical properties 
exhibited by $\mathrm{NH}_{4}{ }^{+}-\mathrm{RDW}-\mathrm{NP}$ host and $\mathrm{M}_{\mathrm{x}} \mathrm{O}_{\mathrm{y}}-\mathrm{NP}$ guest, to rationalize isolated structures by wettability and matured interactions present at any location. Achieved composites have been characterized by PXRD, TEM, ICP-OES, TGA, and nitrogen physisorption. Concentration of protected metallic magnetic and bared inorganic NP has been maintained at $6.48 \mathrm{~g} / \mathrm{L}$ to maximize aimed bonds, despite the high probability of precipitated phases detrimentally reducing the active portion of components.

Colour of supernatants at the end of the experiments, reliably relate with amount of removed MNP from liquid emulsion, varying from dark to light brown, reaching uncoloured state uniquely in aromatic media. Emulsion stability experiments and synthesis of supported solids were done in same screw cap glass vials avoiding sunlight ( $1 \mathrm{~cm}$ of diameter). In line with their metastable nature, suspensions of CoO-NP were handled under stricter inert atmosphere using Schlenk techniques instead (» $3 \mathrm{~cm}$ of diameter).

Lack of attractiveness among starting materials, though lessened into solvated host, precludes [RDW$\mathrm{M}_{\mathrm{x}} \mathrm{O}_{\mathrm{y}}$ ] contacts, except those mediated by wetting interfaces forming well defined [RDW-media- $\mathrm{M}_{\mathrm{x}} \mathrm{O}_{\mathrm{y}}$ ] associations analogous to ones described in stirring protocol using array of solvent adsorbate $\mathrm{CH}_{2+x} \mathrm{Cl}_{2 x}$ $(x=0,1)^{21}$ dipoles. Herein, similar layers are reinforced by stronger chemical bonds expedited by extreme Lewis and Brönsted acidity of ions composing $\mathrm{NH}_{4}{ }^{+}$-RDW surface, formed either under motion or, diffusion (Table 1). A few stable MNP emulsions were employed to explore best experimental conditions. We chose three solvents considered non-polar but, with different chemical permittivity, HP and, SPP values like Toluene, Hexane and, THF (Table SI1). Polar media was modelled with an equimolar mixture of THF/EtOH (absolute), avoiding lack of $10 \mathrm{~nm}-\mathrm{Fe}_{3} \mathrm{O}_{4}-\mathrm{NP}$ dispersibility and, dissolution of $\mathrm{NH}_{4}{ }^{+}$-RDW$\mathrm{NP}$ in pure short chain alcohols $(\mathrm{EtOH}$ and $\mathrm{MeOH})$.

As expected by our initial assumptions, not all media allows for depositing same percentage of MNP, in line with individual emulsion states materialized over time in every continuum, though exact added metallic contents and, mostly shared emulsion state stability during active diffusion time (8-10 hours). $\mathrm{V}_{\text {pore }}$ and $\mathrm{S}_{\mathrm{BET}}$ values for supported $\mathrm{M}_{\mathrm{x}} \mathrm{O}_{\mathrm{y}} / \mathrm{C} @ \mathrm{DWC}$ samples, after diffusion and anaerobic calcination, are depicted in Table 1. Results advance individual free energies for $\left[\mathrm{NH}_{4}{ }^{+}-\mathrm{RDW}\right.$-media], [ $\mathrm{M}_{\mathrm{x}} \mathrm{O}_{\mathrm{y}}{ }^{-}$-media] and, $\left[\mathrm{NH}_{4}{ }^{+}\right.$-RDW-media- $\left.\mathrm{M}_{\mathrm{x}} \mathrm{O}_{\mathrm{y}}\right]$ systems, relating solvates representing a progression in polarity ultimately, defining the precise microstructure of the suspension. $\mathrm{N}_{2}$ isotherms prove that most of produced solids show variable mesoporous and textural characteristics (Figure 1D-E-F). Nitrogen uptakes in solids bearing metallic species, are produced gradually at medium and, sharply at higher pressures evidencing homogeneous wetting interfaces and, overlapping in the actuation of active mesopores. Indeed, absence of a well-defined plateau between $0.2<P / P_{0}<0.6$ corroborates broadening of minor voids reminiscence of original DW-NP microporosity. At first glance, decline of $S_{B E T}$ and $V_{\text {pore, }}$ signal Toluene and, EtOH/THF mixture, as optimal media to encompass defiant $15 \mathrm{~nm}$-host/10 nm-guest approach, indirect connection and, final deposition but unavoidable differences operate in each media as highlighted below (bold, Table 1). 
Table 1: Textural properties of $\mathrm{M}_{\mathrm{x}} \mathrm{O}_{\mathrm{y}}(@ 3,<10) / \mathrm{C} @ D W C$ solids. ${ }^{\mathrm{a}}$

\begin{tabular}{|c|c|c|c|c|}
\hline \multirow[b]{2}{*}{ Mediator } & \multicolumn{2}{|c|}{ Diffusion } & \multicolumn{2}{|c|}{ Vortexed } \\
\hline & $\begin{array}{c}\mathrm{S}_{\mathrm{BET}} \\
\left(\mathrm{m}^{2} \mathrm{~g}^{-1}\right)\end{array}$ & $\begin{array}{c}V_{\text {pore }} \\
\left(\mathrm{cm}^{3} \mathrm{~g}^{-1}\right)\end{array}$ & $\begin{array}{c}\mathrm{S}_{\mathrm{BET}} \\
\left(\mathrm{m}^{2} \mathrm{~g}^{-1}\right)\end{array}$ & $\begin{array}{c}V_{\text {pore }} \\
\left(\mathrm{cm}^{3} \mathrm{~g}^{-1}\right)\end{array}$ \\
\hline \multicolumn{5}{|c|}{$\mathrm{Fe}_{3} \mathrm{O}_{4}(5,58-10.03 \mathrm{~nm})-\mathrm{NP}$} \\
\hline Toluene & 116 & 1.17 & 481 & 1.97 \\
\hline Hexane & 430 & 1.47 & 459 & 1.70 \\
\hline THF & 567 & 1.73 & 475 & 1.52 \\
\hline ETOH+THF & 321 & 1.52 & 515 & 1.22 \\
\hline \multicolumn{5}{|c|}{$\mathrm{CoO}(3 \mathrm{~nm})-\mathrm{NP}$} \\
\hline$o-\mathrm{DCB} / \mathrm{THF}^{\mathrm{b}}$ & 309 & 1.03 & - & - \\
\hline
\end{tabular}

${ }^{\mathrm{a}}$ Bare DWC-NP from $\mathrm{NH}_{4}{ }^{+}-\mathrm{RDW}-\mathrm{NP}$ non poured to any organic media: $\mathrm{S}_{\mathrm{BET}}=491 \mathrm{~m}^{2} \mathrm{~g}^{-1}, \mathrm{Vpore}=1.59 \mathrm{~cm}^{3} \mathrm{~g}^{-1} .28 \mathrm{~b}$ Synthesis done in $o$-DCB media at rt and $50^{\circ} \mathrm{C}$ with similar results. 18

\section{Toluene continuum}

Dramatic low uptake at medium pressures in Toluene sample, evidences triggering of an extra nonnegligible contribution, substantiated like a robust force occurring between aromatic electron rich toluene ring and, exposed ions in $\mathrm{NH}_{4}{ }^{+}$-DW-NP surface (Figure 1D). Considering that is the unique media letting persistently decolorated supernatants at the end of experiments, evincing the absence of dispersed $\mathrm{Fe}_{3} \mathrm{O}_{4}-\mathrm{NP}$, it is obvious that singularity is a p-ion interaction that sinters massively $\mathrm{NH}_{4}{ }^{+}-\mathrm{RDW}-\mathrm{NP}$ host. Fact is unambiguously proven with $\mathrm{V}_{\text {pore }}$ values, emptiness of $11 \mathrm{~nm}$ mesopores, porosity reduction in central $\mathrm{P} / \mathrm{P}_{0}$ values, and justified by sluggish nitrogen kinetics over sintered domains (Table $1 \mathrm{~S}_{\mathrm{BET}}$ and $\mathrm{V}_{\text {pores }}$ measured during adsorption/ desorption and desorption cycles, and Figure 1D).

Stable [Toluene- $\mathrm{Fe}_{3} \mathrm{O}_{4}$-Toluene] system is well documented in bared magnetite surfaces exposed to air, ${ }^{34}$ where nitrogenated $\mathrm{NO}_{2}$ molecules are displaced by the aromatic cycle, potentially settling robust $\mathrm{p}$ cation interactions. Besides, competence of ternary $\left[\mathrm{NH}_{4}{ }^{+}-\mathrm{RDW}\right.$-Toluene- $\left.\mathrm{Fe}_{3} \mathrm{O}_{4}-\mathrm{NP}\right]$ set is done by synergetic likeness of media with alkyl chains, magnetite and host surfaces stablishing interfaces free of repellences, tolerating the steric hindrance of OA and OAm ligands (before calcination step). In those conditions, p-ion might be heightened by low e of surrounded media and microstructure's confinement under diffusion.

Aromatic molecules place so close host and guest in $\left[\mathrm{NH}_{4}{ }^{+}-\mathrm{RDW}-\right.$ Toluene- $\left.\mathrm{Fe}_{3} \mathrm{O}_{4}\right]$ but unfortunately also, host and host onto $\left[\mathrm{NH}_{4}{ }^{+}\right.$-RDW-Toluene- $\mathrm{NH}_{4}{ }^{+}$-RDW] separated by a thin organic layer of sandwiched aromatic rings responsible of the superlative agglomeration. Therefore, trivial separation solves defiant union but at the same time, reduces at the uppermost percentage of available host surfaces, advancing the poor weight in supported magnetite guest traditionally anchored. Subsequently, effective cooperation of forces along $\left[\mathrm{NH}_{4}{ }^{+}-\mathrm{RDW}\right.$-Toluene- $\left.\mathrm{Fe}_{3} \mathrm{O}_{4}\right]$ system is proven with the disappearance of smaller 3-4 nm voids, understood as clogging result of forbidden introduction of non-polar 10.03 $+4.35 /-0.85$ 
$\mathrm{nm}$ magnetite, fierce $\mathrm{p}$-ion interaction force and entry's constriction (Toluene case, diffusion Figure 1B and motion 1D).

There are important differences to remark when experiments are done whether in strict diffusion or, vortexed conditions. In motion, Toluene molecules take the role of 11-mesopores' guest, swelling corresponding framework, simultaneously dispersing pristine $\mathrm{NH}_{4}{ }^{+}-\mathrm{RDW}-\mathrm{NP}$ and annihilating $\left[\mathrm{NH}_{4}{ }^{+}-\mathrm{RDW}-\right.$ Toluene- $\mathrm{NH}_{4}{ }^{+}$-RDW] set, despite of still operational non-cero-quadrupolar moment in external and internal pore walls (Table 1 and Figure 1F). Poor weight of supported OINSP must be rationalized in motion within the no establishment of dipolar interactions anchoring MNP guest, in contrast to diffusion experiments, where the reason must be adjudicated to the scarcity of available non-nanostructured carrier surfaces. In Toluene, p-ion bond originates shelter for guest deposition and host agglomeration but, softer dipolar interactions, ones responsible for the challenging $\mathrm{Fe}_{3} \mathrm{O}_{4}$-NP stabilization, solely survive under diffusion in line to corresponding weak strength.

Predicted homogeneous $\mathrm{NH}_{4}{ }^{+}$-RDW-NP covering with Toluene adsorbates, is verified with high $\mathrm{N}_{2}$ uptakes measured in vortexed experiments at higher $\mathrm{P} / \mathrm{P}_{0}$ ratio and massive sintering under diffusion. Moreover, because emulsions contain detached $\mathrm{NH}_{4}{ }^{+}$-RDW-NP particles, active interporosity events are cancelled in variable extension, leading to potentially more realistic $\mathrm{S}_{\mathrm{BET}}$ values in no presence of stabilized $\mathrm{Fe}_{3} \mathrm{O}_{4}-\mathrm{NP}$ guest despite conceivable covering of carbonaceous residuals (Table 1: 481 versus $491 \mathrm{~m}^{2} \mathrm{~g}^{-1}$ ).

Crucially, $\mathrm{p}$-cation bond has been documented in calcite ${ }^{35}$ bearing adsorbed aromatic hydrocarbons, on oxides as $\mathrm{TiO}_{2},{ }^{36}$ within ammonium cations bonded to protein residues ${ }^{37}$ and, between IA-cations and PHA molecules allowing for singular stereochemical courses in reactions. ${ }^{38}$ In $\mathrm{NH}_{4}{ }^{+}$-RDW-NP periphery, chemical bond could take place like $\mathrm{p}-\mathrm{CO}_{3}{ }^{-2}, \mathrm{p}-\mathrm{Al}^{+3}$ and $\mathrm{NH}_{4}{ }^{+}-\mathrm{p}$ but electronic Toluene's richness delineates a chief p-cation role. In fact, all of them decorate more frequent (010) and (100) surfaces and besides, ammonium cations show rotational disorder amplifying probability towards arbitrary interaction (DFT). ${ }^{39}$ Nonetheless, bulkiness of ammonium strains dawsonite structure facilitating access of exogenous Toluene molecules and, forces fractures contiguous to areas bearing less mechanically stable bonds within liable approach of ions (Figure SI6.1).

Though not considered a truly bond owing to lack of electronic exchange, $\mathrm{p}$-ion interaction results on electrostatics/charge-transfer contributions, reinforced by non-cero-quadrupolar magnetism generated by resonance ring's current, with reported energies ranging from 1 to $40 \mathrm{Kcal} / \mathrm{mol}$ found at the level of certain real chemical bonds. Indeed, resultant vector field of dipole's $\mathrm{NH}_{4}{ }^{+}$-RDW-NP surface might specifically reinforce $\mathrm{p}$-ion interaction, but also might be transmitted over low e toluene media at tiny distances, despite of low m values (Table SI1). Success of local p-ion bond linking opposite polarities, is based in surface's nature amid, $\mathrm{NH}_{4}{ }^{+}$-RDW-NP and $\mathrm{Fe}_{3} \mathrm{O}_{4}-\mathrm{NP}$, fitting interface forces and solvation energies, ${ }^{40}$ within plausible confinement added by emulsion's microstructure, empowering the use of reported process. In fact, reliability towards stated unions is based on four concurrent key factors: 
Superior $\mathrm{p}$-ion strength than in the bulk, reinforcement of intermolecular associations into organized emulsion, lack of drying phenomena and finally, compulsory kinetic adsorption step for hydrophobic guest founded onto weaker molecular interactions. Regrettably, same causes assist to unlimited joining of host $\mathrm{NH}_{4}{ }^{+}$-RDW-NP particles. Though imposed scalar dimensions expedite stronger forces, tiny portion of supported population unambiguously proves materialization of p-ion bond in larger RDW surfaces.

Finally, uncoloured supernatants, quantitative adjoining of wholly added $\mathrm{Fe}_{3} \mathrm{O}_{4}$-NP occurs within diffusion, rationalizing allied embedded condition, and size of magnetite particles argue the no-filling of $11 \mathrm{~nm}$ and minor mesopores at any circumstance (Table 1 and Figure 1D-F).

\section{o-DCB/THF continuum}

Diffusing smaller $<3 \mathrm{~nm}$-CoO-NP guest particles within THF mixed with aromatic $o$-DCB solvent, bearing a ring electronically poorer with a greater quadrupole moment, does not extinguish $\mathrm{NH}_{4}{ }^{+}-\mathrm{RDW}-\mathrm{NP}$ agglomeration. Described persistence might be resolved to complementary establishment of $\mathrm{p}-\mathrm{CO}_{3}{ }^{2-}, \mathrm{p}$ cation and coordination bonds in (010)/(100) $\mathrm{NH}_{4}{ }^{+}$-RDW-NP facets. THF was added to destroy usual spherical CoO-NP aggregates, experimentally observed in $\mathrm{o}-\mathrm{DCB}$, to maximize interaction of individual guest with solvated $\mathrm{NH}_{4}{ }^{+}$-RDW-NP host. ${ }^{18}$ Minor $3 \mathrm{~nm}$ size permits filling of $11 \mathrm{~nm}$ pore rushed by empowered $p$-ion forces occurring inside less polar narrowed spaces. Partial filling must be consequence of clogged voids by sintered host and, high stability of ternary [o-DCB-CoO-NP-THF] system harmonising electronic and magnetic donation through metallic core (Table 1 and Figure 1E). Again, minor voids disappear signalling as reasonable preferential interaction of the aromatic cycle with bare host surface under diffusion (o-DBC/THF case, Figure 1E). Motion has not been tested.

\section{Hexane continuum}

Hexane as mediator demarcates performances resulting from soft forces acting in [Hexane- $\mathrm{NH}_{4}{ }^{+}-\mathrm{RDW}$ ] pair in front of superlative attractiveness over $\left[\mathrm{Fe}_{3} \mathrm{O}_{4}\right.$-Hexane- $\left.\mathrm{Fe}_{3} \mathrm{O}_{4}\right]$ system provided by organic protection of magnetite NP, explaining thus, low metallic depositions, notorious colour of supernatants and, efficient solvation coverings (HP and e, Table SI1). Nitrogen isotherms and BJH distributions show negligible host agglomeration and supported magnetite along with, maintenance of textural properties. Worthy affinity of six carbon chain is well documented on inorganic surfaces in solid state ${ }^{41}$,and solution, ${ }^{42}$ within low surfactant concentration and no competition of adsorbates. Herein, data reveals that equally occurs over $\mathrm{NH}_{4}{ }^{+}$-RDW-NP, evidenced within significative nitrogen uptakes at elevated $\mathrm{P} / \mathrm{P}_{0}$ values at any condition (Figures $1 \mathrm{~F}$ and SI3 for motion and diffusion, respectively). Lack of exact reproducibility onto repeated experiences assigns randomized interaction with minor pores (Figures SI3) and $11 \mathrm{~nm}$ voids with a slight but noticeable $V_{\text {pores }}$ reduction, which must be attributed to a relaxed regulation towards entry, endowed by combined linearity of solvent molecules and, optimal adaptation of torsion $\mathrm{H}-\mathrm{C}-\mathrm{C}-\mathrm{H}$ angles, shrinking width of wetting interfaces (Table 1). Details are associated to the absence of a strong activity supporting guests, being conclusive of the heterogeneous emulsion. 


\section{THF/EtOH continuum}

Superior wettability's of THF/EtOH mixture with nanostructured $\mathrm{NH}_{4}{ }^{+}-\mathrm{RDW}$ carrier, shows a dual benefit, firstly rescinds in great extend related sintering and, secondly, materializes more typical magnetite dispersions supported in carrier surface. Besides, intermolecular interactions between co-solvents in the organized emulsion remarkably withdraw damaging effects of each individual media: abstraction of peripheral host's cations using non-bonded THF electrons under diffusion and, harmful dissolution of host in pure EtOH (SPP and e, Table SI1 and Figure 1D). Solubilized $\mathrm{NH}_{4}{ }^{+}$-DW-NP state has been successfully profited to prove ion-exchange properties in aqueous solutions ${ }^{23}$ which, it is not compatible with data shown in Table 1 (see next section).

In those samples, heterogeneous array of adsorbates, cooperatively heightens coordination and hydrogen

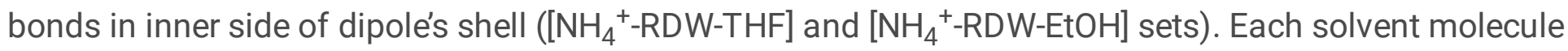
comprises distinctive headgroups and carbon skeletons, materialising segregated domains mimicking polarity of $\mathrm{NH}_{4}{ }^{+}$-RDW surface's but, largely sinking original hydrophilicity into the side intended to absorb supported population as $\left[\mathrm{NH}_{4}{ }^{+}-\mathrm{RDW}-(\mathrm{THF} / \mathrm{EtOH})-\mathrm{Fe}_{3} \mathrm{O}_{4}\right]$. Henceforth, successful anchorage of superparamagnetic guest is evidenced with $\mathrm{S}_{\mathrm{BET}}$ values within vague reduction of minor mesopores, enforcing diffusion conditions to support particles in external periphery due to weak strength of dipolar interactions (Table 1, Figure 1D and F). Henceforward, $S_{B E T}$ values in samples diffused and supported on $\mathrm{THF} / \mathrm{EtOH}$, might be taken as reliable reproduction of the occupied surface periphery by magnetite guest, since voids remain empty in a non-agglomerated alumina (isotherms and loop hysteresis traces THF/EtOH Figure 1D, Table 1).

\section{Miscellaneous}

In accordance with exposed experimental trends, total iron contents determined by ICP-OES are superior in embedded (Toluene) than dispersed samples (EtOH/THF), raising respective values up to 3,30 and $2,73 \%$ Fe wt. in calcined solids. Numbers stress quantitative storage of iron weight within heavily agglomerated carrier and, $82.7 \%$ metallic deposition yield in polar media. Though not optimized, experiments drive as reliable, diffusion techniques in organic solvents, to realize physically defiant host/guest unions, reaching same absolute level than more conventional impregnation and deposition methods. Further, presented protocol adds, the advantageous and rarely available option, for choosing absolute metallic contents in final samples of uncommon morphology, also reported supporting $\mathrm{Au}(0)$-NP onto carbon xerogels. ${ }^{43}$

Offered data launches p-cation, plausible p-anion and, coordination bonds as innovative tool-kit-mode to support hydrophobic particles in polar $\mathrm{NH}_{4} \mathrm{AlCO}_{3}(\mathrm{OH})_{2}$ surfaces, to be converted in amorphous g- $\mathrm{Al}_{2} \mathrm{O}_{3}$. In fact, described cases bolster useful role of reported dipole derived interactions, to real chemical coordination bonds and, non-covalent but robust p-ion influences. Cases exemplify alternative use of organic media beyond more reactive halogenated solvents, showing how to construct real wetting 
interfaces intended to unite non-affine surfaces, eluding highly energetic confrontations and drying phenomena, ${ }^{40}$ with the viable choice of ultimate solid configuration. Suggested high affinity of solvation shelter must be linked to stable and robust interactions between groups of host and media either as donation of lone pair electrons, quadrupolar moment or, electric dipole for which SPhS might offer unvaluable awareness. ${ }^{16,29}$

Next section is devoted to unravel at the deepest actuation mechanism, justifying and demonstrating singularity of each isolated structure, build from identical starting materials.

\section{Interrelated role of cooperative [host-media-guest] assembly governing morphology of final solids}

Well-founded wetting interfaces are required along whole external area of $\mathrm{NH}_{4}{ }^{+}-\mathrm{RDW}-\mathrm{NP}$, intended to be put into contact with hydrophobic $\mathrm{M}_{\mathrm{x}} \mathrm{O}_{\mathrm{y}}-\mathrm{NP}$ guests, to maximize depositions. In all cases, robustness is based on the collective of forces simultaneously consolidating two sides $\left[\mathrm{NH}_{4}{ }^{+}-\mathrm{RDW}\right.$-media- $\left.\mathrm{Fe}_{3} \mathrm{O}_{4}\right]$ networking. Independently of stated reasons, sedimentation of $\mathrm{M}_{\mathrm{x}} \mathrm{O}_{\mathrm{y}}-\mathrm{NP}$ guest into solvation layer, is governed by mass in larger species (gravity), buoyancy in the form of [media- $\mathrm{M}_{\mathrm{x}} \mathrm{O}_{\mathrm{y}}-\mathrm{NP}$ ] pair, viscous resistance of emulsion, Brownian motion and, residual magnetism of guest and host transmitted through selected continuum. Depending on dielectric, conducting and magnetic dissipation factors of each solvent, electromagnetic (EM) waves would be stored, conducted and lost in specific percentages. Despite that such contributions are unknow, real part of permittivity infers the capacity of storage and transmission to be added to small EM enhancement that might be provoked by core-shell $\mathrm{Fe}_{3} \mathrm{O}_{4}^{-}$ protection structure (Table SI1).

Powerful thermodynamics of tight p-ion interaction, add stability to ternary $\left[\mathrm{NH}_{4}{ }^{+}-\mathrm{RDW}\right.$-Toluene- $\left.\mathrm{Fe}_{3} \mathrm{O}_{4}\right]$ system, though already present by exceptional lability of peripheral carrier functions, optimal $\left[\mathrm{Fe}_{3} \mathrm{O}_{4^{-}}\right.$ Toluene- $\left.\mathrm{Fe}_{3} \mathrm{O}_{4}\right]$ and $\left[\mathrm{NH}_{4}{ }^{+}-\mathrm{RDW}\right.$-Toluene- $\mathrm{NH}_{4}{ }^{+}$-RDW] even in presence of long alkyl chains. Gratifyingly, SEM pictures on calcined samples, validate its unlimited success and, consequent loss of nanostructured nature on $\mathrm{g}-\mathrm{Al}_{2} \mathrm{O}_{3}$ phase. In fact, Toluene transform host in a wide distribution of uneven particles, some of them exceeding $50 \mathrm{~mm}$ dimension (Figure 2K). Proven thermal resistance of as-made $<6 \mathrm{~nm}-\mathrm{NH}_{4}{ }^{+}$-DW-NP to agglomerate, confirmed up to $1073 \mathrm{~K},{ }^{23}$ adjudges the crucial actuation of highly exposed acidic/basic sites, distributed at the nanoscale along every bared RDW-NP, profiting directional polarity ongoing in the aromatic cycle. Nonetheless, internal walls of 11 mesopores parallel to $<001>$ axes, copiously covered by $\mathrm{Al}^{+3}, \mathrm{NH}_{4}{ }^{+}$and $\mathrm{CO}_{3}{ }^{2-}$ ions, settle the massive introduction of the flat organic molecules, swollen voids and aggravating typical (010) and (100) breaks. Circumstance is revealed with appearance of terraces in alumina surface, remembering of adjacent $11 \mathrm{~nm}$ RDW channels into DWC structure (Figure 2L).

We decided to do TEM pictures of microtome slices, from calcined materials embedded in Spurr resin, to validate non-usual morphology predicted in Toluene (60 nm thick, Figure 2E-F-G-H, red for Toluene). Yet, pictures show the notorious coalition of metallic centres, occupying inter-cavities putatively left among 
irregular agglomerates of either $\mathrm{NH}_{4}{ }^{+}-\mathrm{RDW}$ (Figures 2E-F, red) or, converted DWC alumina (Figures 3G-H, red). Such dense concentration is assisted by flexibility of ligand's chains in an affine continuum, simultaneous functioning of van der Waals forces, dipole-dipole attractions on superparamagnetic cores of different size and, soften cavity walls sheltered by toluene molecules in accordance with peak attractiveness along $\left[\mathrm{NH}_{4}{ }^{+}{ }^{-} \mathrm{RDW}-\mathrm{Toluene}-\mathrm{NH}_{4}{ }^{+}{ }^{-} \mathrm{RDW}\right],\left[\mathrm{Fe}_{3} \mathrm{O}_{4}{ }^{-}\right.$-Toluene- $\left.\mathrm{Fe}_{3} \mathrm{O}_{4}\right]$ and $\left[\mathrm{NH}_{4}{ }^{+}{ }^{-} \mathrm{RDW}\right.$-Toluene$\mathrm{Fe}_{3} \mathrm{O}_{4}$ ] sequences. Offered reasons deem the continuous entry of hydrophobic guest till the exhaust of entire inner space, conforming characteristic formations observed in pictures enclosed within irregular contours. Then, main portion of metallic guest are loosely buried in DWC host (Figure 3G-H, red) whereas, minoritarian portion is stabilized onto the limited number of surfaces, depicted in pictures as thinner black outlines.

Hexane samples show the closest similarity in traditional depositions with Toluene case, consequence of stable $\left[\mathrm{Fe}_{3} \mathrm{O}_{4}-\mathrm{Hexane}-\mathrm{Fe}_{3} \mathrm{O}_{4}\right]$ set and softer force strength over $\left[\mathrm{NH}_{4}{ }^{+}-\mathrm{RDW}\right.$-Hexane] interface, but disclosing homogeneous solvation in nanostructured $\mathrm{NH}_{4}{ }^{+}$-DWC-NP carrier at any condition (Figures $2 \mathrm{~B}$ and $D$ in blue). In line to it, isotherms accuse preservation of mesoporous properties, with important nitrogen's uptakes at higher pressures, spotted under motion, as Toluene does, adding diffusion conditions (physisorption experiments in $1 \mathrm{~F}$ for motion and SI3 for diffusion samples).

Toluene data predict better performances in terms of host sintering for electronically poorer aromatic solvents like $o$-DBC, despite stronger quadrupole moment and better transmission ability (Table SI1). However, host agglomerates even within softening effect of THF co-solvent. Unexpectedly, presence of 3 nm-CoO-NP can't be discerned in corresponding embedded slice though, broad PXRD peaks over 18 and 25 degrees (2q), delate presence of carbonaceous deposits as seen in $\mathrm{Fe}_{3} \mathrm{O}_{4}(10) / C @ D W C$ samples, implying successful diffusion and stabilization (Figures 2A and SI3 right). Likely oxidation of metallic CoO cores with expelled $\mathrm{CO}_{2}$ throughout $\mathrm{NH}_{4}{ }^{+}$-RDW decomposition, is followed by practical introduction of $\mathrm{Al}^{+3}$ cation into spinel network, forming cobalt aluminates in host surfaces as divergent outcome, previously reported by other authors. ${ }^{44,45}$ Chemical path is aided by putative high dispersion of pristine cobalt species deposited and strained $\mathrm{NH}_{4}{ }^{+}$-RDW-NP lattice owing to bulkiness of ammonium cations $\left(\mathrm{CO}_{3-\mathrm{x}} \mathrm{Al}_{\mathrm{x}} \mathrm{O}_{4} / \mathrm{C} @ D W C\right.$, Figures $2 \mathrm{~A}$ green and $\mathrm{SI} 3$ right). Yet, primary oxidation of CoO-cores is mandatory due to related oxygen deficient nature, small size, confinement along 11-nm, and high temperature.

Addition of a EtOH drop dipping a carbon-coated copper grid, containing Toluene sample before calcination step, releases minor population of hydrophobic guest supported in $\mathrm{NH}_{4}{ }^{+}$-RDW-NP surface, proving the delicate nature of molecular interactions anchoring superparamagnetic centres in the shell conformed by aromatic cycles $\left(\mathrm{Fe}_{3} \mathrm{O}_{4}(10) / \mathrm{OA} / \mathrm{OAm} /\right.$ toluene@ $\mathrm{NH}_{4}{ }^{+}-\mathrm{RDW}$ solids). Though pure EtOH solubilizes host, TEM micrograph clearly shows liberated $\mathrm{Fe}_{3} \mathrm{O}_{4}-\mathrm{NP}$ guest presenting analogous interparticle distances compatible with occurrence of $\mathrm{C}_{18}$ stabilizer's chain (Figure $2 \mathrm{l}$ and inset, red). 
Anaerobic calcination at $723 \mathrm{~K}$, fixes stronger supported populations into $\mathrm{Fe}_{3} \mathrm{O}_{4} / \mathrm{C} @ D W C$ solids, preserving macroscopic morphology of the non-calcined material (Figure 2E-F versus $\mathrm{G}-\mathrm{H}$, red). Carbonization deprives, every metallic magnetite core of the hampering protection, converted in a thin carbonaceous shelter, simultaneously developing competitive bonding networks at each side, separately in contact with respective $\mathrm{Fe}_{3} \mathrm{O}_{4}$ and DWC ( $\mathrm{g}-\mathrm{Al}_{2} \mathrm{O}_{3}$ ) surfaces. In accordance to reported results, carbonaceous shell surrounding metallic cores contain same type of acidic and carbonyl groups, regardless of calcination procedure used (heating in air, ${ }^{21}$ hydrothermal ${ }^{46}$ or, sonication ${ }^{47}$ ), quantified ${ }^{47}$ with intensity of $s t(C=0)$ and $s t(C=C)$ signals $(F T I R)$. Correspondingly, TGA of $\mathrm{Fe}_{3} \mathrm{O}_{4}(10) / C @ D W C$ sample, under nitrogen up to $800^{\circ} \mathrm{C}$, founds a gradual weight loss measuring $8 \%$ for residual organic functions, within identical degradation profile of samples stabilized by a silanol matrix ${ }^{48}$ (red trace, Figure $S I 2$ ). Therefore, same locked guest deposited now in alumina don't detach adding $\mathrm{EtOH}^{21}$ and neither, embedded $\mathrm{Fe}_{3} \mathrm{O}_{4}(10) / \mathrm{C}$-NP population that remains unmeasurable due to physical captivity (Figure $2 \mathrm{~J}$ and inset, red). Last detail emphasizes preservation of identical distributions afterwards calcination step.

During thermal treatment, solvation layer in deep contact with polar surface might act whether as simple spectator as believed to happen with Hexanes or, lively react with external atoms of host forming amorphous $\mathrm{g}-\mathrm{Al}_{2} \mathrm{O}_{3}$ nanoplates, case observed in protic solvents (Figure $2 \mathrm{~B}$ and D versus $\mathrm{C}$ ). Explicit outcome in each described example is consequence of, heterogeneous microstructure of emulsion and reactivity driven by the wetting interface at high temperatures. Former cause reasons the revoking of sintering mechanism, seen in aromatic continuums, into EtOH/THF blend settling adsorbate's shells without affordable chemical bond to link another $\mathrm{NH}_{4}{ }^{+}$-RDW-NP in the other side. In fact, EtOH/THF infer into the highest percentage of untaken host surfaces, to accommodate non-polar guest, featuring then, the greatest relative ratio of supported $\mathrm{Fe}_{3} \mathrm{O}_{4}-\mathrm{NP}$ realized among all media tested $(2.73 \mathrm{Fe} \% \mathrm{wt}$., $\mathrm{R}=82.73 \%$ ). Result launches continuum with highest affinity to host, like the right tool to implant more conventional $\mathrm{Fe}_{3} \mathrm{O}_{4}$-NP dispersions, gratifyingly distinguished in TEM pictures proving thus, the vital building of sturdier solvation imprinting effectiveness to $\left[\mathrm{NH}_{4}{ }^{+}-\mathrm{RDW}-\mathrm{THF} / \mathrm{EtOH}-\mathrm{Fe}_{3} \mathrm{O}_{4}\right]$ collective (Figure $2 \mathrm{C}$ black).

PXRD data sustain amorphous state of host and carbonaceous shell in calcined samples within lack of reflections (Figure 1C). Indeed, crystalline lattice fringes were non-discernible in TEM pictures though homogeneity along samples was verified examining wider areas (Figure SI3). However, background scattering present in all PXRD samples fits discernible (111), (400), and (440) signals, identified as crystalline domains in layered amorphous $\mathrm{g}-\mathrm{Al}_{2} \mathrm{O}_{3}$ alumina, observed in similar solids submitted to superior temperatures of calcination, exactly $773^{32,49}$ in front of $723 \mathrm{~K}$ (herein, Figure $1 \mathrm{C}$ ). Current crystallinity induction is realized onto dried media, because superior amorphization takes place in THF case containing major traces of water and, worse damaging action into $\mathrm{NH}_{4}{ }^{+}$-RDW-NP surface. Results suggest that sturdiest wetting EtOH/THF and Toluene interfaces assist to develop more regular $\mathrm{NH}_{4}{ }^{+}-$ RDW-NP net in the emulsion, equally reflected in massively sintered host after carbonization (Figure 1C). 
Ultimate appearance of alumina in TEM pictures, diffused over more polar blend, reminds small alumina platelets found during crystallization of $\mathrm{NH}_{4}{ }^{+}-\mathrm{RDW}^{31}$ in aqueous media preserving mesoporous properties, thin curved-edge plates like habit of well crystallized $\mathrm{AlOOH}$ boehmite ${ }^{50}\left(\mathrm{Al}_{2} \mathrm{O}_{3} \mathrm{H}_{2} \mathrm{O}\right)$ under different lengths, round/ellipsoid pseudo-boehmite crystals ${ }^{32}\left(\mathrm{Al}_{2} \mathrm{O}_{3} \mathrm{xH}_{2} \mathrm{O}\right.$ where $\left.1.0<\mathrm{x}<2.0\right)$ or, nanoplates similar to ones isolated during hydrolysis of aluminum sec-butoxide carried out in presence of alkyltrimethylammonium surfactants in 1-butanol solution. ${ }^{51}$ Thermal treatment triggers Brönsted acidity of solvated adsorbates in contact with carrier surface, leading to plausible introduction of ethoxy groups into layered structure, presumably endowing a primary derived alkoxide g- $\mathrm{Al}_{2} \mathrm{O}_{3}$ $\mathrm{H}_{2} \mathrm{O} / \mathrm{Al}_{2} \mathrm{O}_{3} \mathrm{EtOH}$ shell (or g-AlOOH/AlOOEt), with a frequency dictated by heterogeneous distribution of shelter induced by polar carrier. Result proves actuation of structural memory effect in samples mediated by EtOH/THF media, strictly authenticating solvation cover in newly formed DWC plates, within irregular size disparity, keeping nanostructured nature after diffusion and calcination. Clearly, origin of microstructure emulsion is the polarity upcoming from $\mathrm{NH}_{4}{ }^{+}$-RDW-NP periphery, which effect has been unambiguously emulated in aqueous media accommodating non-shared Co-spinel distributions, supported during wetness impregnation into amorphous a-, $\tau$ - and $\theta$ - and $g-\mathrm{Al}_{2} \mathrm{O}_{3}$ polymorphs in exact experimental conditions. ${ }^{44}$ Similarly herein is transmittedvia EM waves crossing adsorbate's fence and, couldn't be disregarded acting in synergy with fixed electric dipoles of THF and EtOH molecules from the emulsion.

Conversely, TEM picture depicts, that supported guest under EtOH/THF diffusion, are dispersed over entire surface disponible following relative placements, recognised either as more regular lineal set of magnetite nanoparticles or, agglomerated cores (Figure 3C). Delated structuring might be attributed to the anchorage of particles in selective wetting interface sites, conducted by large stabilizer's chains but, diffused $\mathrm{Fe}_{3} \mathrm{O}_{4}$-NP guest are separated within distances, scaling intrinsic mean $10 \mathrm{~nm}$ diameter retained among corresponding sparsity of the non-symmetric population, like $5.88 \mathrm{~nm} \pm 3.75 \mathrm{~nm}$ scopes (70 counts, SI5D). Result is well-adjusted towards host electronics endowing distinctive sites for settling weak interaction with magnetite NP unhiding EM transmitted though carbonaceous frontiers (magnetite protection and wetting interface), in combination with, permissible size-dependent-location into regular solvation over the whole external surface. Yet, deeper analysis discloses the apparently selective single anchorage for minor nuclearity magnetite NP owing to enhanced magnetic properties of superparamagnetic individuals near $5 \mathrm{~nm}$ boundary $(5.8 \mathrm{~nm}, \mathrm{SI} 5 \mathrm{C})$ and, histogram of sizes for supported individuals don't match one of pristine distribution. Plainly, $18.9 \%$ maintain diameters untouched, $7.7 \%$ represent species bearing 35.0-48.7 nm diameters whilst, resting dimensions don't show any trend. In summary, DWC host stabilizes a dispersion of $19.31+29.38 /-13.82 \mathrm{~nm}$ diameters, crucially including like more frequent events combinations of species conforming original sample distribution (5.6 to 48.7 nm, 156 NP counts, SI5.B).

Described pattern deviation accuses as judicious a size-selective magnetic attraction modulated by viscosity, ${ }^{52}$ in a media able of storing and, conducting electromagnetic fields, allowing attractive 
diffusion, collapse and ultimate agglomeration of hydrophobic guest, ${ }^{53}$ via self-inducing aggregation ${ }^{54}$ or, perceptible chaining organization separated by distances compatible with metallic species fenced by original ligands ${ }^{55}$ and also, without them in smaller guest (Figures 2C-black, SI5 A-C). Data supports significative EM transmissions in high e media while, in low e continuum, conduction must be heightened under confinement, being not assisted by dipoles present in host surface.

Reverse trend in size's dispersion for supported $\mathrm{Fe}_{3} \mathrm{O}_{4}$-NP isolated after EtOH/THF diffusion, in front of original skewed distribution, is singular and, must be empowered by specific EM from host and guest cores, dispersed over liquid emulsion and contained physical frontiers (organic protection and forced gradients). Intriguingly, experimental detail might illustrate one of the growing MxOy-NP mechanisms followed in cases where, EM properties play a major role and, common atomic additions are annihilated, whether via cancelled approach in kinetic variants or, high dilution conditions (Figure 1A versus 2M). Precipitation of guest into carriers conformed by big agglomerates might be contributed by significative mass forces, if non cancelled via buoyancy, not present onto pristine components used here and in more polar media, where deposition has been proven driven by electromagnetic inputs modulated by solvation. This is the way how approach physically avoids highly energetic unfavourable encounters of antagonist materials and, drying events.

Uncovered and buried hydrophobic guests preserve chemical nature and cubic structure with unmeasurable impurities by PXRD (Figure 1C). Despite of containing MNP smaller than $20 \mathrm{~nm},{ }^{56}$ no signals at minor $2 q$ values, strongly suggests non-existence of external g-maghemite shell. Result is more remarkable in Toluene samples because guest enjoy of a worst carrier's protection in agreement with, minor peripheral acidity/basicity and concurrent lack of connexion for main set population (Toluene in front of EtOH/THF samples). Moreover, same data extrapolates no existence of tetragonal contributions consequence of structural spinel strain, when cell parameter starts escalating sharply, ${ }^{56}$ reducing lattice volume. Though, broad signals of carbonaceous deposits and fluorescence events may hide stated peaks, IR authenticates magnetite phase (Experimental data). Scherrer on (311) peak, reflect great variation of $\mathrm{Fe}_{3} \mathrm{O}_{4}$-NP sizes hiding anisotropic inputs associated with distinctive states described for metallic guest. Asymmetric trace might indicate feasible face-stacking amid magnetite NP agglomerated either in cavities or, supported in alumina. As expected, major intensities are linked to diffused Toluene samples superior in absolute weight (Toluene>EtOH/THF>Hexane>THF, Figure 1C).

Reducibility TPR- $\mathrm{H}_{2}$ measurements in $\mathrm{Fe}_{3} \mathrm{O}_{4}(10) / \mathrm{C} @ D W C$ solids of buried configuration show three events over $308^{\circ} \mathrm{C}(51 \%), 452^{\circ} \mathrm{C}(39 \%)$ and $758^{\circ} \mathrm{C}(10 \%)$ correlated with finite MNP size, corresponding carbonaceous shell protection and, complex speciation superposed with interrelated size dependent transformations $\left(4.99 \% \mathrm{H}_{2}\right.$ flow in $\left.\mathrm{N}_{2}, 1024 \mathrm{mmol} \mathrm{H}_{2} / \mathrm{g}\right)$. In these conditions $\mathrm{H}_{2}$ consumption from $\mathrm{NH}_{4}{ }^{+}$ RDW-NP carrier is negligible and, hydrogen depletion couldn't be justified by entire reduction of inorganic cores and organic fence. Numbers allege the "in situ" catalytic Fisher-Tropsch (FTC) production of small hydrocarbons, analogous to the one reported in presence of $\mathrm{H}_{2} / \mathrm{H}_{2} \mathrm{O} / \mathrm{CO}_{2}$ as feed mixture at low temperatures catalysed by $4 \mathrm{~nm}-\mathrm{Fe}_{3} \mathrm{O}_{4}-\mathrm{NP}$ at $250^{\circ} \mathrm{C}^{57}$ and, $14 \mathrm{~nm}-\mathrm{Fe}_{3} \mathrm{O}_{4} / \mathrm{Fe}-\mathrm{NP}$ at $380-540{ }^{\circ} \mathrm{C},{ }^{58}$ 
identifying and increasing inputs over first and second TPR- $\mathrm{H}_{2}$ signals. FTC justify presence of three events instead of the two shown by analogous samples not bearing carbon contents ${ }^{59}$ avoiding also, presence of thermal carbides decomposition. ${ }^{60}$

\section{Highly restrictive in-pores entry imposed by significant wetting interfaces in host and guest}

Metastable adsorption and desorption of non-polar guest, in build wetting-interfacial boundaries throughout $\mathrm{NH}_{4}{ }^{+}$-RDW-NP are kinetic events, founded in weak non-covalent interactions, occurring in synergy with forces responsible of sheltering foundation and, become robust after being transformed in a copious network of mainly hydrogen bonds. Tougher bonds develop more stable self-assembled wettability's, closer to entropically favourable SAM monolayers, ${ }^{61}$ already proven within isolated crystalline segregates at milder temperatures. Further, enunciated stability is vital to cancel disadvantageous effects of permittivity's alterations, otherwise inherent in our handled heterogeneous emulsions. In fact, intrinsically widespread and regular covering of inorganic dawsonite surfaces, is confirmed with experimental intermolecular distances measured between supported guest after diffusion in EtOH/THF co-solvents, colossal agglomerates of amorphous $\mathrm{g}-\mathrm{Al}_{2} \mathrm{O}_{3}$ formed in Toluene, noticeable early alumina crystallinity distinguish and, top nitrogen uptakes during physisorption isotherms for solids coming from diffusion (Hexanes) or, vortexed emulsions (THF, Hexanes, Toluene).

Experimental data mean unavoidable directions to populate RDW mesopores, facilitated by dominant softening of interfacial solvent polarity under confinement, ${ }^{20}$ but with a highly restricted entry for guest. Consequently, more significative $11 \mathrm{~nm}$ voids fillings, happen with smallest $3 \mathrm{~nm}$-CoO-NP guest additionally, proving the radicalization towards permitted introduction due to high volume of $o-D B C$ and THF molecules. Wider in size $\mathrm{Fe}_{3} \mathrm{O}_{4}$-NP guests, do not populate same mesopores, despite containing unsymmetrical fraction between 5.60-6.99 nm, in less hampering Toluene molecules, empathizing introduction and fracture of void's scaffold rather than dwelling. Less encumbering Hexane molecules relax dimensional restrictions within thinner interfaces, justifying the non-practical but perceptible, reduction of $11 \mathrm{~nm}$ volume pore, non-attributable to host sintering (bold in Table 1). In fact, lack of reproduction in a second experiment, delates randomized collisions typical of heterogeneous emulsions but also, might be ascribable to, dissimilar stacking of non-sintered host particles distinguishing adsorption cycles of nitrogen isotherms for non-weighty introduction of magnetite guest's.

Generalized obstruction of minor mesopores, reminiscence of the original microporosity in as-made materials, is inevitable due to two concurrent facts: Size-forbidden-entry in presence of an organic media having great affinity for polar RDW-NP surface, as non-covalent robust $\mathrm{p}$-ion reinforced by quadrupolar magnetism of Toluene and $o$-DBC rings under diffusion (Fig. 1D-E). In vortexed emulsions same phenomenon is provoked by tough coordinative chemical THF bond, exact p-ion in Toluene, and great cooperation amid softer reciprocal influences with methylene groups of Hexanes (Fig. 1F).

\section{Damaging trends of organic media measured onto nanostructured RDW host}


Nanostructured nature in host increases intrinsic vulnerability because at the same time, accentuates strength of the potential interactions to be produced with organic media, greatly exposing sites sensitive to be attacked. Besides, gradual variation of mesoporosity in the strained net, ease the introduction of exogeneous molecules across distorted $\mathrm{NH}_{4}{ }^{+}$-RDW-NP structure, conceiving a major harmful effect. Structural stress in dawsonites structure is clear when pinning IA cations with larger radii, as seen in $\mathrm{Na}^{+}$, $\mathrm{K}^{+}$to $\mathrm{NH}_{4}{ }^{+}$series (Figure 3A-B). Expansion of the unit cell, in stated sequence, is reflected onto corresponding volume and $\mathrm{M}-\mathrm{O}, \mathrm{M}-\mathrm{M}, \mathrm{O}-\mathrm{O}$ distances. leading to non-symmetrical $\mathrm{M}(\mathrm{IA})-\mathrm{O}, \mathrm{O}-\mathrm{O}$ and $\mathrm{M}(\mathrm{IA})$ $\mathrm{M}(\mathrm{IA})$ separations in more distorted cases (Figure $3 \mathrm{~A}-\mathrm{C}, \mathrm{M}=\mathrm{Al}^{+3}, \mathrm{~K}^{+}, \mathrm{Na}^{+}$and $\mathrm{NH}_{4}{ }^{+}$, Al-O distances in Table SI6.1).

Chemical stability shown by $\mathrm{NH}_{4}{ }^{+}$-RDW-NP distributions, into a given media and non-polar guest, is different under diffusion and motion conditions. Since used host $\mathrm{NH}_{4}{ }^{+}-\mathrm{RDW}-\mathrm{NP}$ are closer to the nominal composition, than as-made DW counterparts, it is conceivable to create steady performances during diffusion experiments. Assuming veracity, distinctive performances must be related to the implication of different dimensions, modulating crucially peripheral affinity and reactivity. Less harmful action of any media, in presence of hydrophobic guests, takes place under diffusion, unless stabilization of $p$-ion interactions undeniably sintering $\mathrm{NH}_{4}{ }^{+}$-RDW-NP particles and coordination bonds removing labile cations detached as stable, soluble and, heavily coordinated species to oxygen lone pair of THF ${ }^{62}$ destroying external $\mathrm{NH}_{4}{ }^{+}$-RDW-NP surface under diffusion, while supporting the lowest proportion of hydrophobic guest (Figure 1C). Coordinative unions are reinforced by inherent electric dipole of every solvate molecule, evidenced by SPP and SdP parameters, depicted in Table SI1. In juxtaposition, THF do not harm surface under vortexed conditions, driving smoothly its entire covering, at the same time, obstructing minor pores with guest and cancelling relative depositions (Figure 1F and Table 1).

Dynamic emulsions, illustrated with vortex experiments, signify optimal dispersions of homogeneously individual host $\mathrm{NH}_{4}{ }^{+}$-RDW-NP. Decisively, circumstance demarcates a particular state, where interparticle interactions present in bared dry solids, might be destroyed in great extent $\left(\mathrm{S}_{\mathrm{BET}}\right.$ in Table 1 and physisorption traces in Figure 1F). Though condition is not useful to support metallic guest, it is a valuable meant for the realization of four remarkable measures. First, it is a practical way for determining formal and realistic inferior $\mathrm{S}_{\mathrm{BET}}$ values in solids with significative interparticle porosity in solid state, prospective to be vanished in homogeneous THF, THF/EtOH, Toluene and Hexane emulsions. Importantly, vortexed emulsions show substantial internalization of solvent molecules in mesopores, swelling, and damaging corresponding scaffold, reproduced within higher $\mathrm{S}_{\mathrm{BET}}$ values (Table 1). Specifically, most harmful action occurs in polar THF/EtOH, producing ink-bottle voids of $7 \mathrm{~nm}$, revealed with the mesopores filling over $P / P_{0}>0.6$ values (with or without 3 seconds of ultrasounds, Fig. $1 F$ ). Exception if found in THF adjudicating the more reliable $\mathrm{S}_{\mathrm{BET}}$ value measured at 475 thus, predicting interparticle porosity inputs of used $\mathrm{NH}_{4}{ }^{+}$-RDW-NP at least of $16 \mathrm{~m}^{2} \mathrm{~g}^{-1}$. Unfortunately, in latter number it must be subtracted the contribution of carbonised residuals of media adsorbates left in host surface 
after calcination. In those conditions, non-viable establishment of molecular interactions don't enable the deposition of magnetite NP.

Second, it is a worthy indication for real state of host, because uptakes are proportional to size of corresponding particles and dispersion being thus, a good descriptor for sintering's degree.

Third, physisorption experiments reflect practical affinity of every shell solvation towards absolute nitrogen uptakes at highest $\mathrm{P} / \mathrm{P}_{0}$, defining following order THF>Toluene@Hexane governed by reminiscence of unspoiled $\mathrm{NH}_{4}{ }^{+}$-RDW-NP surface acidity in shelter, bespoke within chemical structure of adsorbates, corresponding polarizability and feasible carrier agglomeration (Fig. 1D-F). And fourth, data unequivocally proves, that bonds with host mediated by tested solvents are settled and, remain stable under both, diffusion and vortexed conditions.

Challenging anchorage via dipole-dipole and derived interactions, is materialized in diffusion minimizing adversity of weak force, too large organic stabilizers on magnetite NP and, non-negligible EM originated by guest and carrier non-stopped by carbonaceous and solvation layers (reflected also in the weight of nitrogen molecules adsorbed). In great contrast, reported solvation layers of halogenated molecules, not rescind stirring conditions, due to two beneficial factors: Shorter alkyl C8 chains and, neutral $\operatorname{Au}(0)$ cores.

Anaerobic combustion is suggested to imprint a slight anisotropic irregularity in $o-D C B / T H F$ sample's voids, consequence of different thermal contraction of cobalt aluminate and alumina phases during calcination (Fig. 1E). Rest of cases don't produce significative changes at $723 \mathrm{~K}$, excluding the usual symmetric differentiation demarcated by alumina and amonium dawsonite nets (inset Figure 1B). $\mathrm{EtOH} / \mathrm{THF}$ solvation layer needs consideration furnishing lath-like particles with transient $\mathrm{AlOO}(\mathrm{H})_{2-\mathrm{x}}(\mathrm{Et})_{\mathrm{n}}$ $(x<1.0)$ surfaces, endowing subsequently amorphous $\mathrm{Al}_{2} \mathrm{O}_{3}$ phase in contrast to $\mathrm{CCl}_{4}$, producing irreversible hydro-dichlorination onto alumina solids between $473-773 \mathrm{~K} .{ }^{63}$

Experimental details empathize the potential complementary amid $\mathrm{CH}_{2-n} \mathrm{Cl}_{2+n}$, Toluene, o-DBC/THF and THF/EtOH coverings to be exploited towards any host/guest pair, to make more effective electrostatics and dispersive forces, founding weak molecular interactions to be optimally produced towards a wide range of carbonaceous functions.

Present job highlights challenges to overcome, when mixing organic solvents and nanostructured $\mathrm{NH}_{4}{ }^{+}-$ RDW, with judicious extension to other hydrotalcite solids. Depending actuation mode of continuum and, strength of interactions stablished, harmful effects could be more notorious within definite conditions and size ranges, non-tested here.

\section{Potential morphology deduction for as-made $\mathrm{NH}_{4}{ }^{+}$-DW-NP and reconstructed $\mathrm{NH}_{4}{ }^{+}-\mathrm{RDW}$-NP samples in ILPD and analogous procedures}

Diffusion experiments presented above, add valuable physical and chemical information about stability and performance of ammonium dawsonite solids in non-usual organic solvents. Main reason for relevant 
absence, must be attributed to the plausible destruction of the solid whether by solubilization, ion's abstraction, unwanted reactivity or, irretrievable distention of porosity scaffold.

Reformed $\mathrm{NH}_{4}{ }^{+}$-RDW-NP from ILPD protocol, used carrier in diffusion tests, is a solid coming from g$\mathrm{Al}_{2} \mathrm{O}_{3}$ calcined at medium temperature ${ }^{28}$ featuring chemical compositions closer to $\mathrm{C}_{1.0} \mathrm{H}_{6.0} \mathrm{~N}_{1.0} \mathrm{O}_{5.0} \mathrm{Al}_{1.0}$ nominal, improving chemical purity of as-made solids and, crystallinity of samples done under pressure (Table SI7). ${ }^{24}$ Performance of solids in diffusion tests reveal presence of different sizes, ascribable also to variable proportion of amorphous and crystalline phases, in agreement with reported characterization state in analogous samples (Table SI9). Ascertain has been further described whether in the form of isolated crystals (ranging among spherical, euhedral, acicular and, rhombic) or, quantitative DS/TGA and EA contents for target phase (though chemical purity is not always thoughtfully specified). Generally, fast mixing conditions endow smaller crystallites enclosed by low surface energy planes (ILPD $<6 \mathrm{~nm}^{23}$ SSMD $<6.1 \mathrm{~nm}^{64}$ and, RSM mixers $<5.1 \mathrm{~nm}^{64}$ ) than those synthetized at higher pressures $\left(<16 \mathrm{~nm}^{24}\right)$ and, mechanically stirred solvothermal reactions ${ }^{33,31,32,65}$ or, in autoclave leading to non-amorphous phases $\left(7 \mathrm{~h}, 180^{\circ} \mathrm{C}\right) .{ }^{66}$

Regardless existence of trustworthy synthetic procedures, controversial and intricate nature for treated solids, has triggered to examine intermediates and, co-existent phases in final products. For instance, $\mathrm{NH}_{4}{ }^{+}$-DW nanorods are isolated simultaneously with non-nominal species, identified as "quasialuminium-hydroxy-carbonates ${ }^{32 "}$, analogous to transients associated with individual enthalpy values like "amorphous ammonium aluminium carbonate hydroxide ${ }^{67 "}$ in ILPD and, "amorphous carbonatecontaining aluminium hydroxide ${ }^{65}$ " in synthesis of Na-counterpart. Focusing onto final materials, a systematic understanding for sort of mixes and, related distributions, is to date lacking. Interestingly, diffusion tests in organic media offer valuable insight to predict operating configurations, before calcination treatment.

Since $\mathrm{pH}$ of precipitation largely affects chemical composition, crystallinity and size of crystals, it is reasonable to envisage the zero charge point of unpolluted $\mathrm{Al}(\mathrm{OH})_{3}$ at $\mathrm{pH}=9$ as optimal condition, to enhance the required anionic/cationic diffusion and intercalation furnishing aimed phase. Despite of it, most of reported synthesis are carried out between pH of 7 and 8 (Table SI7), leading to similar DSC values: $42 \%(\mathrm{pH}=8.5),{ }^{65} 50 \%\left(\mathrm{pH}=7.5-8^{23}\right.$ and $8^{23}$ ILPD) but also, $\mathrm{pH}=10.5^{32}$ furnishing pure $\mathrm{NH}_{4}{ }^{+}-\mathrm{DW}$ nanorods, evidencing an alternative specie as real starting source or, precursor. Precipitation for ammonium dawsonite occurs consequence of favourable Gibbs free energy in front of resting species present $\left(D G(298 \mathrm{~K})=-1564 \pm 2^{68} \mathrm{KJ} / \mathrm{mol}\right.$ and $\mathrm{DG}(353 \mathrm{~K})=-1483.0^{69} \mathrm{KJ} / \mathrm{mol}$, reported for divergent mixing times and temperatures).

It has been suggested, that reconstruction of dawsonite phase is conducted via a solubilizationprecipitation process, fastened rising temperatures. Detail rationally conceives $\left[\mathrm{Al}(\mathrm{OH})_{4}\right]^{-}\left(\mathrm{or} \mathrm{AlO}_{2}^{-}\right)$like primary building blocks, either forming straight-forwardly described intermediates or, conforming chains of octahedral aluminium cations where well-adjusted ionic-intercalations follow. In the specific case 
of ammonium dawsonite solids, smaller crystallites delivered from highly homogeneous reactive emulsions, ensue maintenance in dimensions onto products, decreasing reaction barriers and facilitating the integration of diffused ions separating $\mathrm{Al}$ atoms from same double chain, when reducing the sizes of integrated particles (Figure SI6.3). Specifically, small size and poor quality of PXRD data relate boehmite ${ }^{69}$ solids and $\mathrm{NH}_{4}{ }^{+}-\mathrm{DW}^{24}$ done under exogenous pressure (Figure $3 \mathrm{~A}$ and $\mathrm{C}$, Table SI6.2). In line to it, $\mathrm{g}-\mathrm{Al}_{2} \mathrm{O}_{3}$ is usually produced via thermal dehydration of boehmite and, target dawsonite phase has been synthetized using more soluble pseudo-boehmite ${ }^{70}$ as source material. However, reported point of zero charge at $\mathrm{pH}=11.38 \pm 0.15$, in the surface of aluminium oxide-hydroxide nanolayer as pseudoboehmite analogue over $\mathrm{pH}=3-8,{ }^{71}$ is out of fitting to experimental conditions carried out in ILPD reactions invalidating potential correspondence (calculated high zeta potential $\zeta \geq 50 \mathrm{mV}$ ). Again, formation enthalpies for pure phases support chief $\mathrm{NH}_{4}{ }^{+}$-DW/RDW crystallization in front of boehmite, extensively approving proposed soluble sources as ultimate source (vacuum with loosely bound water $\mathrm{DH}_{\text {formation }}($ boehmite $)=104.1 \pm 0.4(22)^{72} \mathrm{KJ} / \mathrm{mol} \mathrm{DH}^{\circ}{ }_{\text {formation }}$ (boehmite) $=-985.5 \pm 0.9^{72}$ $\mathrm{KJ} / \mathrm{mol}$ with Surface Area of $274 \pm 4(3) \mathrm{m}^{2} / \mathrm{g}$; $\left.\mathrm{DH}_{\text {formation }}{ }\left(\mathrm{NH}_{4}{ }^{+}-\mathrm{DW}-\mathrm{NP}\right)=-1655^{39} \mathrm{KJ} / \mathrm{mol}\right)$.

Dealing with ILPD and derived fast contacting blenders, mixing times are crucial not only for, controlling textural properties via formal pores and crystallite sizes but also because, vital role provoking local supersaturation spots in the reactive media, driving nucleation and growth rates upholding memory effect. Importantly, experimental parameter imply occurrence of organized gradients of co-existent phases that might be materialized in boehmite, pseudo-boehmite, aluminium hydroxy-carbonates (with or without ammonium), $\left[\mathrm{Al}(\mathrm{OH})_{4}\right]^{-}$, solvated alumina and, pure ammonium dawsonite in proportions dependent on reaction times and, experimental conditions followed. Besides, every phase might present individual reaction rates, that would maintain the heterogeneity of the distribution. In described mix, kinetically trapped and perfectly ordered states preserving memory effect, might sustain close energies, reducing thermodynamical force to growth of larger crystals. Indeed, dispersion might enable the augmentation of Lewis and Brönsted properties, whether by influence of contiguous ion or, less hindered approach in unsaturated sites. Assembly of offered materials must be dictated by known memory phenomenon, permitting subtitle irregularities, smoothed by viable interconnection of sizes and affinities. Equilibria and electroneutrality, are a must in offered distributions, sustaining intermolecular interactions modulated by experimental conditions during synthesis (heterogeneity of stirring power, rpm rate, effective residence time, active insolubility of product), washing, calcination and recrystallization steps done in the aqueous reactive media with, nature distribution of dispersed solids and related peripheral state. Circumstances rationalize isolated solids, not matching nominal composition, because encompass a dispersion of putative phases in its place and, conceives reactive solutions cooperatively organized to derive into final materials.

Assertion is in entire agreement with experimental reforming ${ }^{67}$ and stability experiments of ammonium dawsonite in water (evolving to boehmite, cation-exchanged dawsonite ${ }^{69}$ or hydroxide salts), well-known equilibria of polytypic aluminium oxy(hydroxide), solvated alumina modifications or, aluminium 
hydroxides bearing inner monovalent $\mathrm{HCO}_{3}{ }^{-}$and external divalent $\mathrm{CO}_{3}{ }^{2-}$ at zero point charge condition, ${ }^{73}$ prospecting liable the predicted co-existence of variable proportions for crystalline and gelatinous constituents. Consequently, speciation present might be complex not only pondering the nature of every specie existent but also, foreseeing explicit spatial dispersion, resulting eventually into memory recognized distributions of ammonium dawsonite intermediates and products, related by sluggish kinetics. Lethargic transformations might be speeded increasing fraction's solubility, either raising low framework density character and/or $\mathrm{S}_{\mathrm{BET}}$, via significative porosity broadening, amorphous nature, exogenous thermal inputs and ultimately, fast mixing conditions. Persistent actuation of memory effect advises as minor the contribution of gelatinised sols, since representing a non-negligible structural mismatch with crystalline compositions.

Consistently, pouring described samples into low permittivity solvents should annihilate the common $\mathrm{AlOOH}$ (aqueous) presence at $\mathrm{pH}=6$, unless protic short chain alcohols materializing pseudo- ${ }^{74}$ or boehmite ${ }^{51}$ crystals. Further, protic/non-protic organic solvents cancel formation of $\left[\mathrm{Al}(\mathrm{OH})_{4}\right]^{-}\left(\mathrm{or} \mathrm{AlO}_{2}{ }^{-}\right)$ species, as well as, polymerization of aluminium derivatives typically accounted in presence of aqueous carbonates, expected to be substituted by $\mathrm{p}$-ion or coordination links, stronger under the confinement of emulsion's microstructure in non-aqueous media. Understandably, zones more exposed to the action of the organic continuum whether by accessible allocation within supramolecular association or, presenting inferior levels of local supersaturation, would produce thin boehmite/alumina like-domains in protic solvents and presence of water traces, overspreading a net of carbonate and ammonium ions neutralising charges before calcination step. Irrefutably, uncovered peripheral functions, decided exclusively by specific arrangement, will determine physical performance of samples in every tested organic media. Accordingly, information grasped, during and after diffusion tests, could help into prognostication for active solid ILPD morphology: Establishment of lossy agglomerates conformed by concentric distributions, more irregular gradients or alternatively, segregated crystals surrounded by single ions (Figure 3D). Unfortunately, relative inner migrations will invalidate early estimates in certain cases, to avoid non-affine high interfacial Gibbs energy confronts with organic media. Alleged states might be detected by characterization techniques but, couldn't be unambiguously quantified "in situ". This relevant aspect might be of intricate resolution and, is beyond the scope of present manuscript. Inevitable harmful outcomes, as $\mathrm{NH}_{4}{ }^{+}$-RDW-NP sintering, have been openly enumerated in previous section.

Gratifyingly, allied skeleton density for succeeding alumina and original $\mathrm{NH}_{4}{ }^{+}-\mathrm{RDW}$ solid, ${ }^{23}$ clearly demonstrates the active ionic association, during recrystallization and formation steps, when memory effect is reached assisted by a likely sanctioned diffusion along $\mathrm{pH}$ gradients, viscosity, steric hindrance of ammonium cation and electrostatic boundaries in aqueous media (ILPD). Strong wetting interfaces of organic solvents, formally assist in the realisation of a less amorphous alumina, otherwise expected after several calcination steps. Scenario is compatible with cancelled interparticle porosity via robust Toluene and $\mathrm{EtOH} / \mathrm{THF}$ blends solvation during diffusion tests, improving regularity of memory effect dispersion in certain crystallographic spots, building a more crystalline layered g- $\mathrm{Al}_{2} \mathrm{O}_{3}$ alumina. 
Enumerated experimental facts anticipate, as the most credible arrangements for real as-synthetized and reformed ILPD samples, ones shown in Figure 3D, foreseeing ammonium dawsonite cores surrounded by single ions in solids closer to nominal composition and, ammonium aluminium hydroxides carbonates in as-made solids organized within memory effect (namely $<6 \mathrm{~nm}-\mathrm{NH}_{4}{ }^{+}-\mathrm{DW}$, Figure 3D). Yet, reformed samples from less rigid alumina lattices must conform the purest crystalline ammonium dawsonite cores surrounded, if present, by gradient mixes of described phases and conjoined single ions, when calcination is done at $\mathrm{T}<500^{\circ} \mathrm{C}$, denoted as $<15 \mathrm{~nm}-\mathrm{NH}_{4}{ }^{+}-\mathrm{RDW}$ (low T) being identified as used starting material, capable of reducing alumina amorphization. Intermediate calcination's conditions define reasonably small grain sizes, broadening minor pore distributions and, maintaining $S_{\mathrm{BET}}$ in entire agreement with offered characterisation data. ${ }^{23}$ Moreover, hashing thermal treatments increase presence of segregated alumina areas, raising grain boundary putatively up to $50 \mathrm{~nm}$ in certain conditions. Samples non-entirely reformed, are adjudicated to alumina calcined at higher temperatures $(T<1073 \mathrm{~K})$, predicting cores richer in separated $\mathrm{Al}_{2} \mathrm{O}_{3}$ domains with difficult solubilization ( $<50 \mathrm{~nm}-\mathrm{NH}_{4}{ }^{+}-\mathrm{RDW}$ high $\mathrm{T}$, non-used here). Proposed morphologies agree with experimental spherical shapes in tinier species, substituted by rhombic and, hexagonal forms onto bigger crystals (Figure 3D), supporting real core composition, dimensions, crystallinity and porosity states for isolated crystals reported in distinct synthesis (Table SI7). As far as we know, this is the first time where strict arrangements of chemical phases, are proposed to trail proven memory effect, supportively implementing heterogeneous distributions in isolated solids, simultaneously justifying experimentally identified intermediates.

Massive sintering, measured in Toluene and o-DCB/THF media, points for a host containing an outsized set of accessible $\mathrm{Al}^{+3}, \mathrm{NH}_{4}{ }^{+}$and $\mathrm{CO}_{3}{ }^{2-}$ during active diffusion to external and inner surfaces of carrier mesopores, under reasonable competitive facet's surface to volume ratios in $<15 \mathrm{~nm}-\mathrm{NH}_{4}{ }^{+}$-RDW (low T) species and, non-forbidden permeation. Good dispersibility of non-calcined solids in any tested continuum under motion highpoints ready and favourable interactions, despite practical borderline gradients unbalancing the pure phase. In accordance, more harmful sintering and damaging actions are developed by pure solvents conformed by aromatic cycles and molecules with lone pairs, describing faster diffusions across putative distribution grades, either interacting with single ions, soluble aluminium/ammonium species $\left(\left[\mathrm{A}(\mathrm{OH})_{4}{ }_{\mathrm{n}}^{-}(\text {Solvent })_{\mathrm{y}}\right]^{+3}\right.$ where $\mathrm{y}<2, \mathrm{~A}=\mathrm{Al}^{+3}, \mathrm{NH}_{4}{ }^{+}$and solvent $=\mathrm{THF}$, Toluene, $o-D B C)$, uncovered (010) and (100) facets well-suited in ammonium dawsonite crystals or, 11 $\mathrm{nm}$ voids. In fact, rupture of inner $11 \mathrm{~nm}$ mesopores, seen following Toluene diffusion, exposes new surfaces, improving dispersion over aromatic continuum.

Crucially, knowing that for one hand, used host has been submitted to two consecutive cycles of reconstruction/calcination, and for a second hand, that robust wetting interfaces, disseminated along the whole solid structure increment slightly crystalline segmentation in developed alumina (Figures $1 \mathrm{C}$ and 2C-E-H). Used $<15 \mathrm{~nm}$-RDW-NP (low-medium T) host is supplied as functional synthon in diffusion test on organic media, converting exposed cations and anions embedded mainly in crystalline facets, as effective anchorage spot for solvent molecules, to originate, strictly speaking a more regular alumina 
than one isolated from $<6 \mathrm{~nm}-\mathrm{NH}_{4}{ }^{+}-\mathrm{DW} .{ }^{23}$ Greater rigidity putative of $<15 \mathrm{~nm}$-RDW-NP network submitted to four thermal treatments, advocates for the notorious proportionality between absolute weight of pure dawsonite phase, in crystallites linearly organized within the action of robust wetting interfaces, mimicking layered structure of ultimate alumina. Therefore, crucial microscopic state of alumina, is delineated regardless corresponding macroscopic appearance at the end of diffusion experiments (sintered or layered states).

Remarkably, present job extends proven memory effect like suggested organization along reactive aqueous media surviving, fast mixing aqueous conditions and, subsequent diffusion in organic media unrelatedly with phases present. Strong bonds amidc $\mathrm{NH}_{4}{ }^{+}$-DW-NP and selective organic media represent an effective solvation, assisting to vaguely reduce amorphous state of isolated alumina solids, and not a harmful interaction (Toluene and EtOH/THF mixes).

\section{Conclusions}

Precise control of interactions driven by nanostructured hydrotalcite derived host over organic media, founds basic microstructure of the emulsion, containing materials to be united and, corresponding wetting interfaces, fiercely solving the pristine lack of affinity and promoting singular united configurations. Non-optimized absolute metallic contents are at the level of common impregnation methods. Control over whether challenging deposition of hydrophobic MxOy-NP guest, in the highly hydrophilic surface transformed in lathlike mesostructures of irregular contour or, the embedding within huge alumina agglomerates, has been clearly demonstrated. Success for defiant anchorage is the robust link stablished with continuum and polar $\mathrm{NH}_{4}{ }^{+}$-DW-NP host surface, extending common interfacial dipoledipole and dispersive interactions for building adsorbates array, to stronger chemical coordination bonds and p-ion interactions. Procedure offers as ultimate inductors for approach, electromagnetic forces driving microstructure of emulsion at the nanoscale while, coverings mainly depend on strong bonds settled with functions of host surface. In comparison, common depositions, into host with superior dimensions, are additionally assisted by mass attraction introduced by latter.

Success in solvation coverings is proven with $\mathrm{N}_{2}$ uptakes at higher $\mathrm{P} / \mathrm{P}_{0}$ in not agglomerated host, under vortexing conditions not useful for practical deposition. Remarkably, circumstance paves the way to measure realistic $S_{B E T}$ in solids full of permanent dipoles in external periphery, bearing important contributions of interparticle porosity, further aggravated by intricated compositions. To do so, experiments must be done in motion and, divergent continuums are viable ranging from those with great affinity under soft influences (Hexanes), to ones capable of interacting through p-ion (aromatic) or, coordination bonds reaching polar mixes able to maximize dispersion of the two counterparts to be joined (EtOH/THF). New diffusion protocol permits to choose exact amount of metal contents to be buried onto cubic alumina, into morphology that remains how hematite and other minerals are hosted by bauxite, though transported by flooding water under earth. 
Besides, availability of a plethora of solvents and quantum size starting materials might enable the isolation of alternative configurations, that will be reported in the shorter period plausible, bearing guest sustaining amphiphilic nature, and focusing also in properties of bared host. No less important, slight polarity of build adsorbates shell might be fine-tuned with continuum choice, towards supplementary polarizability scales in wetting interfaces, founded in dipolar, p-ion forces or, truly coordination bonds. Stated advantages are priceless when combined with a potential catalytic application, demonstrating practical utility of diffusion protocol and, results of both configurations will be presented in due course.

Manuscript settles defiant host/guest joining, under most simplistic and affordable conditions, involving hydrophobic and hydrophilic materials, with the aim of divulging present data like preliminary results.

\section{Methods}

Solvents were deoxygenated using common techniques based on inert atmosphere and, acquired from Aldrich with analytical grade purity (treated and stored using Solvent Purification System). Hexane was acquired as mixture of isomers $85 \%$ (hexane/isohexane). Fe(acac) 3 , 1,2-hexadecanediol, oleic acid, oleyl amine, phenyl ether, TEMPO, $\mathrm{Co}_{2}(\mathrm{CO})_{8}, \mathrm{o}-\mathrm{DCB}, \mathrm{Al}\left(\mathrm{NO}_{3}\right)_{3} \cdot 9 \mathrm{H}_{2} \mathrm{O},\left(\mathrm{NH}_{4}\right)_{2} \mathrm{CO}_{3}$ were acquired from Aldrich. All other chemicals were used as received from commercial resources. Spurr resin was chosen owing to established ability to maintain pristine, structural morphologies after corresponding infiltration for samples of diverse nature, ranging from minerals to biological specimens. ${ }^{75}$ Microtomy slicing has been demonstrated to maintain chemical (IR signals), elasticity and geometry of NP properties. Size histograms calculated using open source imaging processing source ImageJ. ${ }^{76}$

Preparation of Fe nanoparticles $\mathrm{Fe}_{3} \mathrm{O}_{4}(10 \mathrm{~nm}) / \mathrm{OA} / \mathrm{OAm}$

$\mathrm{Fe}_{3} \mathrm{O}_{4}$-NP were synthesized following reported methods with experimental variations: Briefly, $\mathrm{Fe}(\mathrm{acac})_{3}(2$ $\mathrm{mmol})$, 1,2-hexadecanediol (10 mmol), oleic acid (6 mmol), oleyl amine $(6 \mathrm{mmol})$ and, deoxygenated benzyl ether $(20 \mathrm{ml})$ were mixed and magnetically stirred under $\mathrm{N}_{2}$. The mixture was heated at $\sim 200^{\circ} \mathrm{C}$ for $2 \mathrm{~h}$ and, additionally subjected to reflux $\left(\sim 250^{\circ} \mathrm{C}\right)$ for $1 \mathrm{~h}$ to isolate skewed distribution. Afterwards, absolute deoxygenated $\mathrm{EtOH}(40 \mathrm{ml})$ was added at room temperature, and a black solid was separated by decantation. Then, product was dissolved in hexane in the presence of oleic acid $(0.5 \mathrm{~mL})$ and reprecipitated with absolute $\mathrm{EtOH}$ to give $\mathrm{Fe}_{3} \mathrm{O}_{4}(5.60-10.88 \mathrm{~nm}) / \mathrm{OA} / \mathrm{OAm}$. Finally, black solid was washed with $\mathrm{EtOH}(3 \times 40 \mathrm{~mL})$ and dried at low pressure with a blanket of nitrogen.

Elemental analysis: \% $\mathrm{N}=0.04, \% \mathrm{C}=11.64 \%$, \% $=1.80 . \mathrm{IR}\left(\mathrm{cm}^{-1}\right)=3358.2,3057.5,3025.68,2960.2$, $2920.1,2848.5,1700,8,1602.5,1466.3,1293.6,860.9,786.2,753.2,693.4,584.0$. TGA; $50-900{ }^{\circ} \mathrm{C}, 10$ ${ }^{\circ} \mathrm{C} / \mathrm{min}$, under $\mathrm{N}_{2} ; 3.5520 \mathrm{mg}$ (\% weight loss, $\mathrm{T}^{\circ} \mathrm{C}$ ): 8.57 (250), 17.23 (420). TEM: $10.03 \mathrm{~nm} \pm 0.85 / 4.35$ $\mathrm{nm}$ (427 counts). UV-Vis $\left(350-850 \mathrm{~cm}^{-1}\right)=$ No absorption signal. 
Preparation of $\mathrm{NH}_{4}{ }^{+}-\mathrm{RDW}-\mathrm{NP}$ host

Ammonium aluminium carbonate hydroxide was synthesized by co-precipitation at constant $\mathrm{pH}$ using the in-line dispersion-precipitation (ILDP) method. Briefly, aqueous solutions of $\mathrm{Al}\left(\mathrm{NO}_{3}\right)_{3} \cdot 9 \mathrm{H}_{2} \mathrm{O}(1.1 \mathrm{M})$ and, the precipitating agent $\left(\left(\mathrm{NH}_{4}\right)_{2} \mathrm{CO}_{3}, 2 \mathrm{M}\right)$ were continuously fed to the miniaturized precipitation chamber (volume of ca. $6 \mathrm{~mL}$ ), which was stirred at $13500 \mathrm{rpm}$. The synthesis was carried out at pH 8 with an average residence time of $18 \mathrm{~s}$. The resulting slurry was aged at $333 \mathrm{~K}$ for $3 \mathrm{~h}$, followed by filtration, washing and drying at $333 \mathrm{~K}$ for $12 \mathrm{~h}$. As-synthesized $<6 \mathrm{~nm}-\mathrm{NH}_{4}{ }^{+}$-DW-NP was calcined under nitrogen at $523 \mathrm{~K}$ during $2 \mathrm{~h}$ using a heating rate of $5 \mathrm{~K} \mathrm{~min}^{-1}$, leading to the formation of amorphous galumina (DWC) which was subsequently treated in a $1 \mathrm{M}$ aqueous solution of $\left(\mathrm{NH}_{4}\right)_{2} \mathrm{CO}_{3}$ at $323 \mathrm{~K}$ for 30 minutes $(\mathrm{pH}=10)$. The treated samples were filtered, thoroughly washed with deionized water until the $\mathrm{pH}$ of the filtrate was 7 , and dried at $333 \mathrm{~K}$ for $12 \mathrm{~h}$. $\mathrm{S}_{\mathrm{BET}}: 586 \mathrm{~m}^{2} \mathrm{~g}^{-1} . \mathrm{V}_{\text {pore }}: 1.32 \mathrm{~cm}^{3} \mathrm{~g}^{-1} .{ }^{67}$ This solid denoted $\mathrm{NH}_{4}{ }^{+}$-RDW-NP was used as host in diffusion experiments in presence of hydrophobic guest. Anaerobic calcination under nitrogen at $723 \mathrm{~K}$ during $2 \mathrm{~h}$ (heating rate of $5 \mathrm{~K} \mathrm{~min}^{-1}$ ) forms g-alumina (DWC) with following characterization data: $\mathrm{S}_{\mathrm{BET}}: 491 \mathrm{~m}^{2} \mathrm{~g}^{-1} . \mathrm{V}_{\text {pore: }}: 1.59 \mathrm{~cm}^{3} \mathrm{~g}^{-1}$.

Preparation of $\mathrm{Fe}_{3} \mathrm{O}_{4}(10) / \mathrm{C} @ D W C$

A dispersion of $10 \mathrm{~nm} \mathrm{Fe} \mathrm{O}_{4} / \mathrm{OA} / \mathrm{OAm}$ (14.6 $\mathrm{mg}$ of $\mathrm{Fe}_{3} \mathrm{O}_{4}$-NP in $0.75 \mathrm{ml}$ toluene) was added to an emulsion formed by $150 \mathrm{mg}$ of $\mathrm{NH}_{4}{ }^{+}-\mathrm{RDW}$ in the minimum volume of same solvent to produce stated state $(£ 1.5 \mathrm{ml})$. Turned handily during 3 seconds and, kept in absence of light and movement for @10 h. Concentration of metallic guest into diffusion conditions is $6.48 \mathrm{~g} / \mathrm{L}$. After that time, supernatant solution, with or without nanoparticles was removed, cleaning softly solid once with exact media (0.5 $\mathrm{mL}$ ). Resultant solid was dried first with a flow of nitrogen and after under reduced pressure for a minute to isolate $\mathrm{Fe}_{3} \mathrm{O}_{4} / \mathrm{OA} / \mathrm{OAm} / \mathrm{S} @ D W$ (where $\mathrm{S}$ denotes solvent molecules). Solid was calcined under $\mathrm{N}_{2}$ at $723 \mathrm{~K}$ for $2 \mathrm{~h}$ furnishing $\mathrm{Fe}_{3} \mathrm{O}_{4}(10) / \mathrm{C} @ D W C$. Elemental analysis: $\% \mathrm{~N}=0.01, \% \mathrm{C}=0.64 \%, \% \mathrm{H}=0.04$. TGA; $50-900{ }^{\circ} \mathrm{C}, 10^{\circ} \mathrm{C} / \mathrm{min}$, under $\mathrm{N}_{2} ; 3.5520 \mathrm{mg}$ (\% weight loss, $\mathrm{T}^{\circ} \mathrm{C}$ ): 7.47 (145), 8.0 (150-460 gradual loss). TEM: $10.03 \mathrm{~nm}+0.85 /-4.35 \mathrm{~nm}$ (Toluene); $19.31 \mathrm{~nm}+29.38 /-13.82 \mathrm{~nm}$ (156 counts, EtOH/THF). PXRD (311): 11.5 and $9.5 \mathrm{~nm}$ in $\mathrm{Fe}_{3} \mathrm{O}_{4} / \mathrm{C} @ D W C$ made in EtOH/THF and Toluene, respectively. ICP-OES: $2.73 \%$ Fe wt. (EtOH/THF); 3.30\% Fe wt. (Toluene). See Table $1 \mathrm{~S}_{\mathrm{BET}}$ and $\mathrm{V}_{\text {pore }}$ and Figure 2 for TEM pictures.

Preparation of $\mathrm{Al}_{2} \mathrm{Co}_{2} \mathrm{O}_{5} @ D W C$ 
CoO nanoparticles were prepared following reported procedures ${ }^{18}$ and, used in situ to diffuse with no physical absolute drying under strict anaerobic atmosphere. In short, $\mathrm{Co}_{2}(\mathrm{CO})_{8}(0,13 \mathrm{mmol})$ was dissolved in $O$-DCB and after addition of TOPO $(0,027 \mathrm{mmol})$, oleic acid $(0,13 \mathrm{mmol})$ and TEMPO $(0,52$ $\mathrm{mmol}$ ) solution was hold at room temperature or warmed to $50^{\circ} \mathrm{C}$ for 30 minutes. Acetone was added, at room temperature, to precipitate nanoparticles and supernatant was removed under inert atmosphere. Then, first $0.75 \mathrm{~mL}$ of deoxygenated $o$-DCB/THF blend was added followed by a dispersion of $\mathrm{NH}_{4}{ }^{+}-\mathrm{RDW}$ (formed by $150 \mathrm{mg}$ of $\mathrm{NH}_{4}{ }^{+}$-DW in $1.5 \mathrm{ml}$ of deoxygenated $o$-DCB/THF). Final emulsion was kept in the absence of light for @10 h under inert atmosphere in a slenchk (traces of acetone might be present). Afterwards, supernatant solution and solid were dried first with a flow of nitrogen and after, under reduced pressure for a minute. Calcination under $\mathrm{N}_{2}$ at $723 \mathrm{~K}$ for $2 \mathrm{~h}\left(\mathrm{ramp} 5^{\circ} \mathrm{C} / \mathrm{min}\right)$ lead to $\mathrm{Al}_{2} \mathrm{Co}_{2} \mathrm{O}_{5} @ D W C$ sample. Characterization, see Table 1 for $\mathrm{S}_{\mathrm{BET}}$ and $\mathrm{V}_{\text {pore }}$ and Figure 2A for TEM picture.

\section{Characterization}

Chemical composition of presented solids was determined by Inductively Coupled Plasma- Optical Emission Spectroscopy (ICP-OES) in a Perkin-Elmer Optima 3200RL (radial) and by Elemental analysis ( $\mathrm{H}$, $\mathrm{C}$, and $\mathrm{N}$ ) performed in a Carlo Erba EA1108 instrument. Before analysis, the solids were dissolved in a 3:1 $\mathrm{HCl}: \mathrm{HNO}_{3}$ solution. Transmission electron microscopy (TEM) was carried out in a JEOL JEM-1011 microscope operated at 100-80 kV and equipped with a SIS Megaview III CCD camera. A few droplets of the sample suspended in ethanol were placed on a carbon-coated copper grid followed by evaporation at ambient conditions. For TEM analysis, the particles were embedded in Spurr's epoxy resin and ultra-thin sections $(60 \mathrm{~nm})$ were cut with a Reichert Ultracut E ultramicrotome (Leica Microsystems), using a Diamond knife (Diatome ultra $45^{\circ}$ ). Thermogravimetry was measured in a Mettler Toledo TGA/SDTA851e microbalance. The solid was placed in a-alumina crucibles without dilution and, analyses were performed

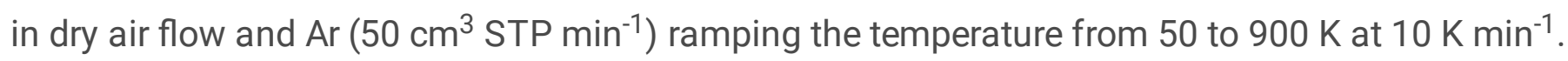
Powder X-ray diffraction patterns were acquired in transmission using a Bruker AXS D8 Advance diffractometer equipped with a $\mathrm{Cu}$ tube, a $\mathrm{Ge}(111)$ incident beam monochromator $(\mathrm{I}=1.541 \mathrm{~nm})$, and a Vantec-1 PSD. Data were recorded in the $2 q$ range of $5-70^{\circ}$ with an angular step size of $0.016^{\circ}$ and a counting time of $6 \mathrm{~s}$ per step. $\mathrm{N}_{2}$ adsorption-desorption isotherms at $77 \mathrm{~K}$ were measured on a Quantachrome Autosorb 1-MP analyser. Before analysis, the samples were degassed in vacuum at $393 \mathrm{~K}$ for $16 \mathrm{~h}$. The BET method ${ }^{77}$ was applied to calculate the total surface area and the t-plot method ${ }^{78}$ was used to discriminate between micro and mesoporosity. $\mathrm{H}_{2}$-TPR $4.99 \% \mathrm{H}_{2}$ in $\mathrm{N}_{2}$. Ramp $10^{\circ} \mathrm{C} / \mathrm{min}$. Temperature from 20 to 900 or $1000^{\circ} \mathrm{C}$.

Data availability. Additional characterization data is available in the Supporting information. 


\section{References}

1. Wu, S. W. \& Jiang, C. Z. Designed synthesis and surface engineering strategies of magnetic iron oxide nanoparticles for biomedical applications. Nanoscale 8, 19421-19474 (2016).

2. Russo, N., Fino, D., Saracco, G. \& Specchia, V. N2O catalytic decomposition over various spineltype oxides. Catal. Today 119, 228-232 (2007).

3. Cheng, W. et al. Lattice-strained metal-organic-framework arrays for bifunctional oxygen electrocatalysis. Nat. Energy 4, 115-122 (2019).

4. Zhang, Y. et al. Characterization of Fe Substitution into La-Hexaaluminate Systems and the Effect on N2O Catalytic Decomposition. J. Phys. Chem. C118, 1999-2010 (2014).

5. Kaczmarczyk, J. et al. Thermodynamic Stability, Redox Properties, and Reactivity of Mn304, Fe304, and Co304 Model Catalysts for N2O Decomposition: Resolving the Origins of Steady Turnover. ACS Catal. 6, 1235-1246 (2016).

6. Hevia, M. A. G. \& Pérez-Ramírez. Assessment of the low-temperature EnviNOx variant for catalytic N2O abatement over steam-activated FeZSM-5. Appl Catal B Environ. 77, 248-254 (2008).

7. Pan, K. L., Yu, S. J., Yan, S. Y. \& Chang, M. B. Direct N2O decomposition over La2NiO4-based perovskite-type oxides. J. Air Waste Manag. Assoc. 64, 1260-1269 (2014).

8. Obalová, L. et al. Catalytic decomposition of nitrous oxide over catalysts prepared from Co/MgMn/Al hydrotalcite-like compounds. Appl. Catal. B Environ. 60, 289-297 (2005).

9. Parres-Esclapez, S., Illán-Gómez, M. J., de Lecea, C. S.-M. \& Bueno-López, A. On the importance of the catalyst redox properties in the $\mathrm{N} 2 \mathrm{O}$ decomposition over alumina and ceria supported Rh, $\mathrm{Pd}$ and Pt. Appl. Catal. B Environ. 96, 370-378 (2010).

10. Kuboňová, L. et al. Catalytic activity of rhodium grafted on ordered mesoporous silica materials modified with aluminum in N2O decomposition. Catal. Today 257, 51-58 (2015).

11. Pannopard, P. et al. Structures, energetics and reaction mechanisms of nitrous oxide on transition-metal-doped and -undoped single-wall carbon nanotubes. ChemPhysChem 13, 583-587 (2012).

12. Gonçalves, F., Marnellos, G. E., Efthimiadis, E. A. \& Figueiredo, J. L. Simultaneous N2O and no reduction over carbon supported catalysis. React.Kinet.Catal.Lett. 80, 153-159 (2003).

13. Zhang, X., Cunningham, M. M. \& Walker, R. A. Solvent Polarity at Polar Solid Surfaces: The Role of Solvent Structure. J. Phys. Chem. B 107, 3183-3195 (2003). 
14. Oh, K.-I. \& Baiz, C. R. Molecular heterogeneity in aqueous cosolvent systems Molecular heterogeneity in aqueous cosolvent systems. J Chem Phys 152, 190901 (2020).

15. Grzybek, G. et al. Influence of preparation method on dispersion of cobalt spinel over alumina extrudates and the catalyst deN2O activity. Appl Catal B Env. 210, 34-44 (2017).

16. Zhang, L., Cullen, D. A., Zhai, P. \& Ding, K. Adsorption of Colloidal Metal Nanoparticles via Solvent Engineering. ACS Catal. 10, 2378-2383 (2020).

17. Zhu, J. et al. Encapsulation of Metal (Au, Ag, Pt) Nanoparticles into the Mesoporous SBA-15 Structure. Langmuir 19, 4396-4401 (2003).

18. Lagunas, A., Mairata i Payeras, A., Jimeno, C., Puntes, V. F. \& Pericàs, M. A. Low-temperature synthesis of $\mathrm{CoO}$ nanoparticles via chemically assisted oxidative decarbonylation. Chem Commun 1307-1309 (2006) doi:10.1039/B517812F.

19. Ochs, M., Mohammadi, R., Vogel, N. \& Andrieu-brunsen, A. Wetting-Controlled Localized Placement of Surface Functionalities within Nanopores. Small 1906463, 1906463 (2020).

20. Dragoi, B. et al. Controlling the distribution of cobalt oxide nanoparticles in the dual pore system of SBA-15 scaffolds Microporous and Mesoporous Materials Controlling the distribution of cobalt ( oxide ) nanoparticles in the dual pore system of SBA-15 scaffolds. Microporous Mesoporous Mater. 224, 176189 (2017).

21. Zheng, N. \& Stucky, G. D. A General Synthetic Strategy for Oxide-Supported Metal Nanoparticle Catalysts. J Am Chem Soc 128, 14278-14280 (2006).

22. Jabłońska, M. \& Palkovits, R. Nitrogen oxide removal over hydrotalcite-derived mixed metal oxides. Catal. Sci. Technol. 6, 49-72 (2016).

23. Stoica, G. \& Pérez-Ramírez, J. Reforming Dawsonite by Memory Effect of AACH-Derived Aluminas. Chem. Mater. 19, 4783-4790 (2007).

24. Dubert, D. C., Pérez-Ramírez, J. \& Garcia-valls, R. Continuous Synthesis of Porous Ammonium Dawsonite Within a New Microstructrured System. Chem. Eng. Trans. 25, 231-236 (2011).

25. Nakaya, M., Nishida, R. \& Muramatsu, A. Size control of magnetite nanoparticles in excess ligands as a function of reaction temperature and time. Molecules 19, 11395-11403 (2014).

26. Sun, S. \& Zeng, H. Size-Controlled Synthesis of Magnetite Nanoparticles. J. Am. Chem. Soc. 124, 8204-8205 (2002).

27. Lattuada, M. \& Hatton, T. A. Functionalization of Monodisperse Magnetic Nanoparticles. Langmuir 23, 2158-2168 (2007). 
28. Stoica, Georgiana., Pérez-Ramírez, J. \& Institut Català d'Investigació Química. Chemistry of dawsonites and application in catalysis doctoral thesis. TDX (Tesis Doctorals en Xarxa) (Universitat Rovira i Virgili], 2010).

29. Jansat, S. Insight into chemical speciation based on solvent physical parameters: Illustration study using octahedral Pt(IV) complexes in several organic media. Chem. Phys. Lett. 686, 148-154 (2017).

30. G, M., C, S., S, J., S, B. \& P, W. Adsorption of colloidal platinum nanoparticles to supports: charge transfer and effects of electrostatic and steric interactions. Langmuir ACS J. Surf. Colloids 30, (2014).

31. Lafficher, R. et al. Ammonium aluminium carbonate hydroxide $\mathrm{NH} 4 \mathrm{Al}(\mathrm{OH}) 2 \mathrm{CO} 3$ as an alternative route for alumina preparation: comparison with the classical boehmite precursor. Powder Technol. 320, 565-573 (2017).

32. Li, G. C., Liu, Y. Q., Guan, L. L., Hu, X. F. \& Liu, C. G. Meso/macroporous Y-Al2O3 fabricated by thermal decomposition of nanorods ammonium aluminium carbonate hydroxide. Mater. Res. Bull. 47, 1073-1079 (2012).

33. Hu, X. et al. Fabrication of high-surface-area y-alumina by thermal decomposition of AACH precursor using low-temperature solid-state reaction. Mater. Res. Bull. 47, 4271-4277 (2012).

34. Eltouny, N. \& Ariya, P. A. Enhanced reactivity toward oxidation by water vapor: Interactions of toluene and NO2 on hydrated magnetite nanoparticles. J. Phys. Chem. C118, 23654-23663 (2014).

35. Wang, H., Grant, D. J., Burns, P. C. \& Na, C. Infrared Signature of the Cation- $\pi$ Interaction between Calcite and Aromatic Hydrocarbons. Langmuir 31, 5820-5826 (2015).

36. Wu, W.-C., Liao, L.-F., Lien, C.-F. \& Lin, J.-L. FTIR study of adsorption, thermal reactions and photochemistry of benzene on powdered Ti02. Phys Chem Chem Phys 3, 4456-4461 (2001).

37. Orabi, E. A. \& Lamoureux, G. Cation- $\pi$ Interactions between Quaternary Ammonium lons and Amino Acid Aromatic Groups in Aqueous Solution. J. Phys. Chem. B 122, 2251-2260 (2018).

38. Zhang, J., Luzyanin, K. V. \& Jansat, S. Potassium-mediated stereochemical assistance to form one indenonaphthacene isomer from rubrene with complementary diastereoselectivity to the acid based protocol. Org. Chem. Front. 3, 1074-1079 (2016).

39. Łodziana, Z., Stoica, G. \& Pérez-Ramírez, J. Reevaluation of the Structure and Fundamental Physical Properties of Dawsonites by DFT Studies. Inorg. Chem. 50, 2590-2598 (2011).

40. Lum, K., Chandler, D. \& Weeks, J. D. Hydrophobicity at Small and Large Length Scales. J. Phys. Chem. B 103, 4570-4577 (1999). 
41. Spataro, G., Champouret, Y., Florian, P., Coppel, Y. \& Kahn, M. L. Multinuclear solid-state NMR study: a powerful tool for understanding the structure of $\mathrm{ZnO}$ hybrid nanoparticles. Phys Chem Chem Phys 20, 12413-12421 (2018).

42. Nanoparticle decoration with surfactants: Molecular interactions, assembly, and applications. Surf. Sci. Rep. 72, 1-58 (2017).

43. Ribeiro, A. P. da C., Martins, L. M. D. R. de S., Carabineiro, S. A. C., Figueiredo, J. L. \& Pombeiro, A. J. L. Gold Nanoparticles Deposited on Surface Modified Carbon Xerogels as Reusable Catalysts for Cyclohexane C-H Activation in the Presence of CO and Water. Molecules 22, 603-615 (2017).

44. Grzybek, G., Ciura, K., Gudyka, S. \& Grybos, J. On the selection of the best polymorph of Al2O3 carriers for supported cobalt nano-spinel catalysts for $\mathrm{N} 2 \mathrm{O}$ abatement: an interplay between preferable surface spreading and damaging active phase-support interaction. Catal Sci Technol 7, 5723-5732 (2017).

45. Klegova, A. et al. Cobalt Oxide Catalysts on Commercial Supports for N2O Decomposition. Chemical Engineering \& Technology vol. 40 (2017).

46. Ao, Y., Xu, J., Fu, D., Ba, L. \& Yuan, C. Deposition of anatase titania onto carbon encapsulated magnetite nanoparticles. Nanotechnology 19, 405604 (2008).

47. Bae, H. et al. Carbon-coated iron oxide nanoparticles as contrast agents in magnetic resonance imaging. Nanoscale Res. Lett. 7, 44 (2012).

48. Villa, S., Riani, P., Locardi, F. \& Canepa, F. Functionalization of Fe304 NPs by silanization: Use of amine (APTES) and thiol (MPTMS) silanes and their physical characterization. Materials 9, (2016).

49. Yalfani, M. S., Santiago, M. \& Pérez-Ramírez, J. In situ studies during thermal activation of dawsonite-type compounds to oxide catalysts. J Mater Chem 17, 1222-1229 (2007).

50. Souza Santos, P., Vieira Coelho, A. C., Souza Santos, H. \& Kunihiko Kiyohara, P. Hydrothermal synthesis of well-crystallised boehmite crystals of various shapes. Mater. Res. 12, 437-445 (2009).

51. Márquez-alvarez, C., Žilková, N., Pérez-pariente, J. \& Čejka, J. Synthesis, characterization and catalytic applications of organized mesoporous aluminas. Catal. Rev. Sci. Eng. 50, 222-286 (2008).

52. Huang, Z. et al. Facile synthesis of size tunable Fe304 nanoparticles in bisolvent system. Chem. Phys. Lett. 664, 219-225 (2016).

53. Jin, D. \& Kim, H. Agglomeration Dynamics of Magnetite Nanoparticles at Low Magnetic Field Gradient. Bull. Korean Chem. Soc. 39, 729-735 (2018). 
54. Yeap, S. P., Leong, S. S., Ahmad, A. L., Ooi, B. S. \& Lim, J. On Size Fractionation of Iron Oxide Nanoclusters by Low Magnetic Field Gradient. J. Phys. Chem. C118, 24042-24054 (2014).

55. Ong, G. et al. Solution synthesis and novel magnetic properties of ball-chain iron nanofibers. J. Mater. Res. 26, 2590-2598 (2011).

56. Frison, R. et al. Magnetite-Maghemite Nanoparticles in the $5-15 \mathrm{~nm}$ Range: Correlating the Core-Shell Composition and the Surface Structure to the Magnetic Properties. A Total Scattering Study. Chem. Mater. 25, 4820-4827 (2013).

57. Zheng, S., Sun, J., Song, D., Chen, Z. \& Chen, J. The facile fabrication of magnetite nanoparticles and their enhanced catalytic performance in Fischer-Tropsch synthesis. Chem. Commun. 51, 11123-5 (2015).

58. Wang, $\mathrm{H}$. et al. Carbon dioxide hydrogenation to aromatic hydrocarbons by using an iron/iron oxide nanocatalyst. Beilstein J. Nanotechnol. 5, 760-769 (2014).

59. Amrousse, R., Tsutsumi, A., Bachar, A. \& Lahcene, D. N2O catalytic decomposition over nanosized particles of Co-substituted Fe304 substrates. Appl. Catal. Gen. 450, 253-260 (2013).

60. Wang, H. et al. Carbon dioxide hydrogenation to aromatic hydrocarbons by using an iron/iron oxide nanocatalyst. Beilstein J. Nanotechnol. 5, 760-769 (2014).

61. Lee, H. J., Jamison, A. C. \& Lee, T. R. Surface Dipoles: A Growing Body of Evidence Supports Their Impact and Importance. Acc. Chem. Res. 48, 3007-3015 (2015).

62. Wang, X. et al. Electric Dipole Descriptor for Machine Learning Prediction of Catalyst SurfaceMolecular Adsorbate Interactions. J. Am. Chem. Soc. 142, 7737-7743 (2020).

63. Yashnik, S. A. et al. Temperature effect on the physicochemical properties of $\chi$-alumina interaction with CCl4. Catal. Sustain. Energy 4, 36-51 (2017).

64. Lafficher, R. et al. Influence of micromixing time and shear rate in fast contacting mixers on the precipitation of boehmite and NH4-dawsonite. Chem. Eng. Sci. 175, 343-353 (2018).

65. Scholtz, E. C., Feldkamp, J. R., White, J. L. \& Hem, S. L. Properties of carbonate-containing aluminum hydroxide produced by precipitation at constant pH. J. Pharm. Sci. 73, 967-973 (1984).

66. Wang, F., Zhu, J. \& Liu, H. Urea controlled hydrothermal synthesis of ammonium aluminum carbonate hydroxide rods. AIP Adv. 8, 035103 (2018).

67. Stoica, G., Groen, J. C., Abelló, S., Manchanda, R. \& Pérez-Ramírez, J. Reconstruction of dawsonite by alumina carbonation in ( $\mathrm{NH} 4) 2 \mathrm{CO} 3$ : Requisites and mechanism. Chem. Mater. 20, 39733982 (2008). 
68. Lafficher, R. et al. Thermodynamic approach of the NH4-dawsonite solubility. in Récents Progrès en Génie des Procédés vol. 111 (2019).

69. Stoica, G. \& Pérez-Ramírez, J. Stability and inter-conversion of synthetic dawsonites in aqueous media. Geochim. Cosmochim. Acta 74, 7048-7058 (2010).

70. Zhao, Z. et al. Preparation of pseudo-boehmite through the dawsonite as an intermediate. Inorg. Nano-Met. Chem. 50, 1094-1102 (2020).

71. Kaledin, L. A., Tepper, F. \& Kaledin, T. G. Pristine point of zero charge (p.p.z.c.) and zeta potentials of boehmites nanolayer and nanofiber surfaces. Int. J. Smart Nano Mater. 7, 1-21 (2016).

72. Majzlan, J., Navrotsky, A. \& Casey, W. H. Surface entalphy of Boehmite. Clays Clay Miner. 48, 699-707 (2000).

73. Scholtz, E. C., Feldkamp, J. R., White, J. L. \& Hem, S. L. Point of Zero Charge of Amorphous Aluminum Hydroxide as a Function of Adsorbed Carbonate. J. Pharm. Sci. 74, 478-481 (1985).

74. Bye, G. \& Robinson, J. The Nature of Pseudoboehmite and its Role in the Crystallization of Amorphous Aluminum Hydroxide. J. Appl. Chem. Biotechnol. 24, 633-637 (1974).

75. Spehner, D., Drillien, R., Proamer, F. \& Hanau, D. Embedding in Spurr's resin is a good choice for immunolabelling after freeze drying as shown with chemically unfixed dendritic cells. J. Microsc. 207, 14 (2002).

76. Rueden, C. T. et al. ImageJ2: Image J for the next generation of scientific image data. BMC Bioinformatics 18, 1-26 (2017).

77. Brunauer, S., Emmett, P. H. \& Teller, E. Adsorption of Gases in Multimolecular Layers. J. Am. Chem. Soc. 60, 309-319 (1938).

78. Lippens, B. Studies on pore systems in catalysts V. The t method. J. Catal. 4, 319-323 (1965).

79. Momma, K. \& Izumi, F. VESTA for three-dimensional visualization of crystal, volumetric and, morphology data. J. Appl. Crystallogr. 44, 1272-1276 (2011).

80. Fernandez-Carrasco, L. \& Rius, J. Synthesis and crystal structure determination of hydrated potassium dawsonite from powder diffraction data. Eur J Miner. 18, 99-104 (2006).

81. Frueh, A. J. \& Golightly, J. P. The crystal structure of dawsonite $\mathrm{NaAl}(\mathrm{CO})(\mathrm{OH}) 2$. Can. Mineral. 9, 51-56 (1967).

82. Bokhimi, X., Toledo-Antonio, J. A., Guzmán-Castillo, M. L. \& Hernández-Beltrán, F. Relationship between Crystallite Size and Bond Lengths in Boehmite. J. Solid State Chem. 159, 32-40 (2001). 


\section{Declarations}

\section{Acknowledgements}

Authors gratefully acknowledge Dr. Georgiana Stoica for RDW samples and SEM picture, Dr Sònia Abellò for anaerobic calcinations, $\mathrm{N}_{2}$ isotherms and BJH pore distributions and, Dr. Jordi Benet-Buchholz for PXRD measurements of supported materials. Dr. Ana Lagunas is thanked for useful comments. We are indebted to Servei de Recursos Cientifics i Tècnics (SRCiT) and ICIQ for the use of their facilities. This research did not receive any specific grant from funding agencies in the public, commercial, or for-nonprofit sectors.

\section{Author contributions}

S.J. performed synthesis of MNP and supported solids. M.M. conducted Spurr dispersions with corresponding TEM pictures (supported materials). S.J. did resting TEM pictures. S.J conceived, designed experiments and, wrote manuscript.

\section{Competing interests}

The authors declare no competing interests.

\section{Figures}




\section{SYNTHETIC SEQUENCE}
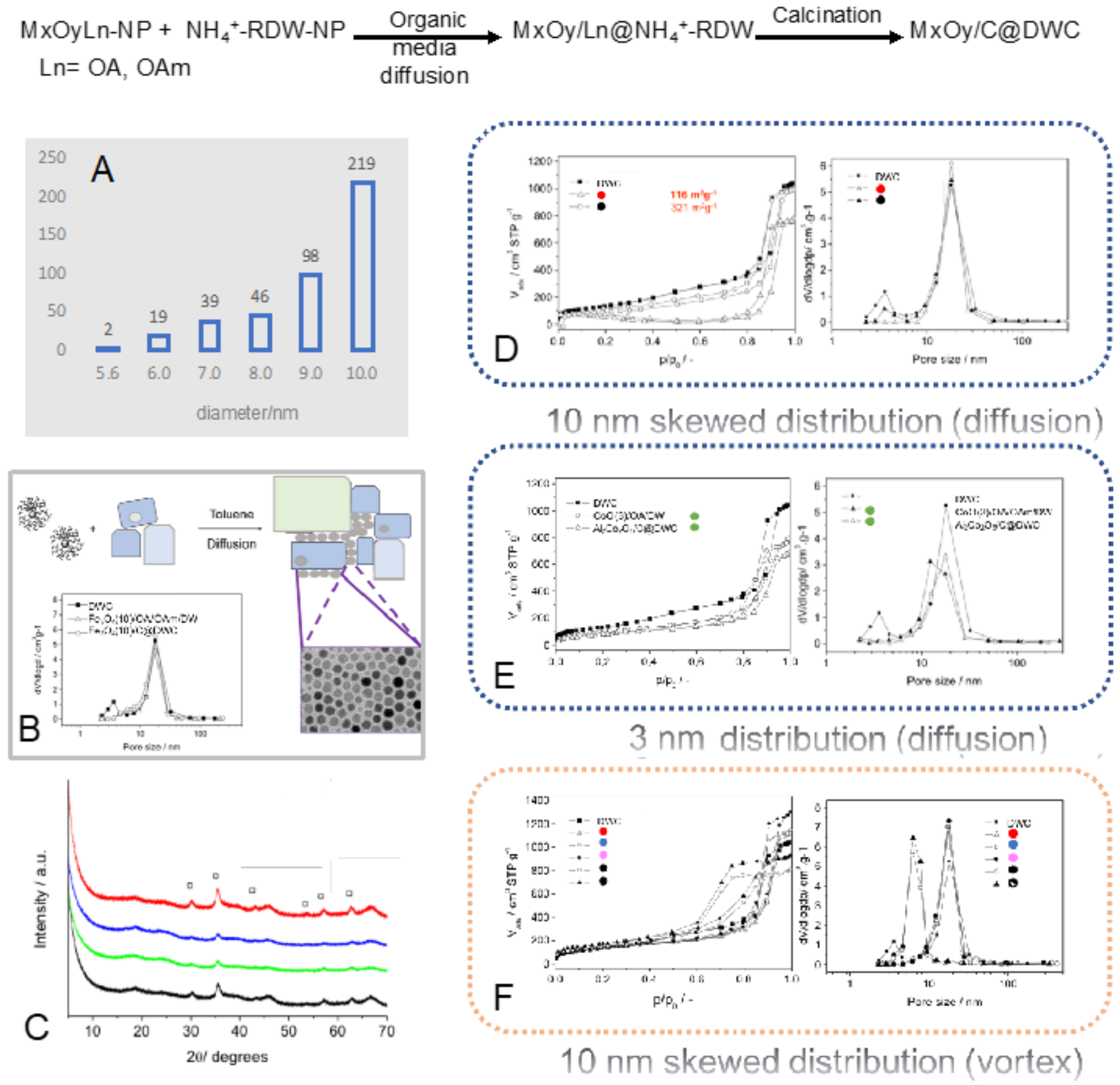

Figure 1

Characterization of pristine and diffusion supported solids. (A) Size histogram of skewed magnetite distribution used in all experiments. (B) Synthetic step of supported solids in toluene using 10/15 nm nanoparticles of host and guest. Inset shows BJH pore distribution for calcined DWC host, freshly prepared Fe3O4 (10)/OA/OAm/Toluene/NH4-DW solid (NH4-RDW: NH4AICO3(OH)2) and, calcined sample Fe304/C@DWC (DWC=囚-Al203 from RDW-NP). TEM picture corresponds to pristine $10 \mathrm{~nm}$ Fe304-NP used as metallic source to be diffused (SI5). (C) PXRD pattern of Fe304(10)/C@DWC carried out under diffusion. Reflections (2ם) marked with a square correspond to Fe304 phase. Red: Toluene. 
Blue: Hexane. C: THF. D: THF/EtOH. (D-F) N2 Isotherms at $77 \mathrm{~K}$ and BJH pore size distributions for supported solids done under diffusion conditions squared in grey ( $<3$ and $<10$. nm MNP) and, orange for vortexing conditions ( $<10 \mathrm{~nm}$ MNP). DW stands for RDW used as carrier in diffusion experiments. Red: Toluene; Blue: Hexane; Pink: THF; Green: o-DCB/THF; Black: THF+EtOH; Black with white: THF+EtOH+ultrasounds (3 seconds). Vpore measured during desorption cycle.
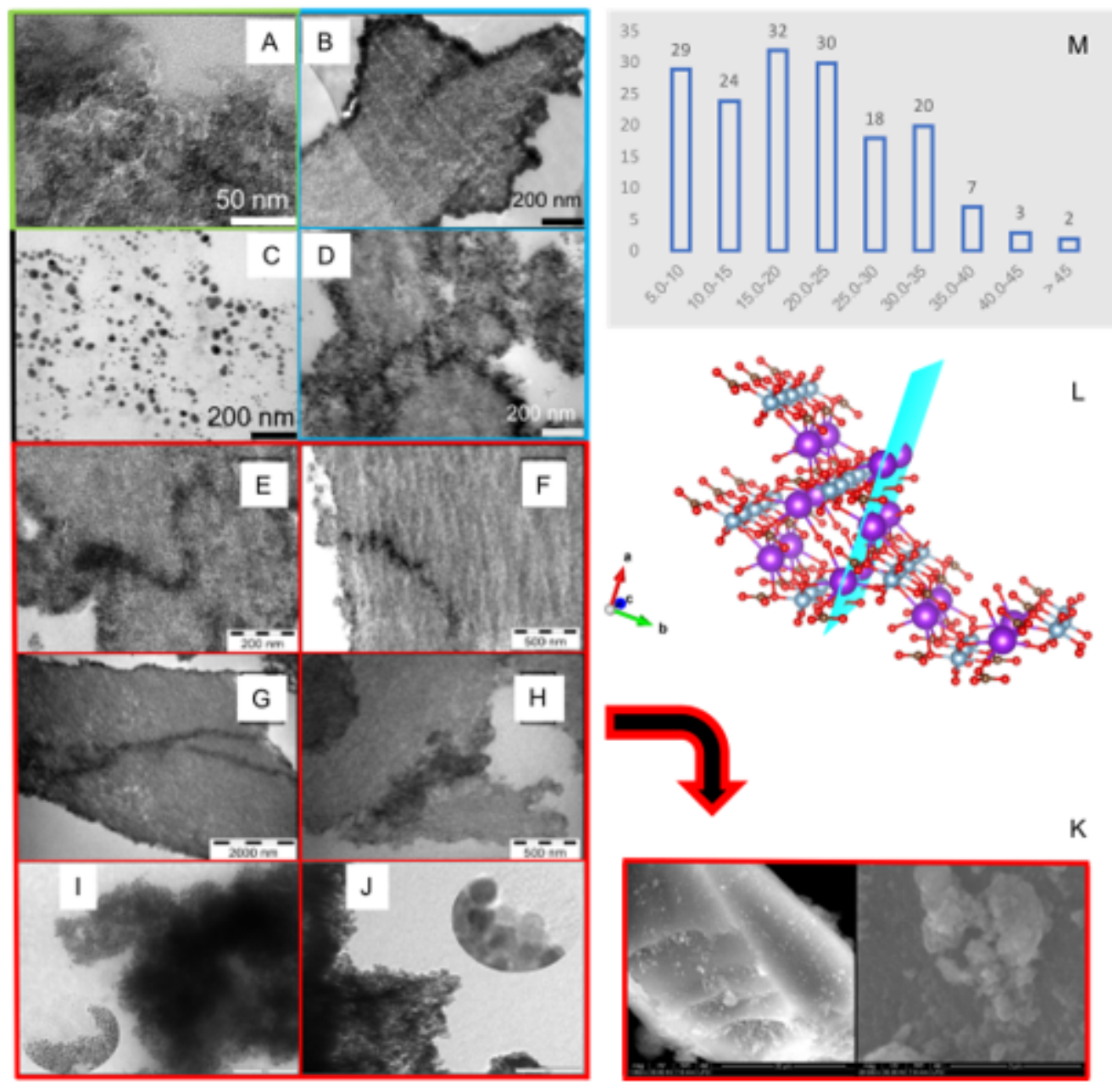

Figure 2

Morphology of isolated solids in unveiled functioning mechanism along each organic media. (A-J) TEM micrographs of samples embedded in Spurr resin (60-nm slices). (A) Al2Co205/C@DWC (green, oDCB/THF); (B, D) Fe304(10)/C@DWC (blue, Hexane); (C) Fe304(10)/C@DWC (black, EtOH/THF, See SI5C); (E-F) Fe304(10)/OA/OAm/Toluene@RDW; (red, Toluene); (G-H) Fe304(10)/C@DWC (red, Toluene). (I) Addition of EtOH drops to non-calcined Fe304(10)/OA/OAm/Toluene@RDW (red, Toluene), and (J) calcined Fe304(10)/C@DWC (red, Toluene) solids. (K) SEM micrographs of powdered Fe304(10)/C@DWC sample suspended in ethanol and, placed on a carbon-coated copper grid followed by evaporation. Corresponding to G-H TEM pictures. (J) Schematic rationalization of peripheral terraces mirroring adjacent $11 \mathrm{~nm}$ mesopores along <001> axe highlighting more frequent (010) fracture highlighted in blue in isomorphic $\mathrm{K}$ dawsonite derivative. Image edited with VESTA software.79 (M) Ultimate guest distribution isolated in alumina using polar EtOH/THF mixture. 


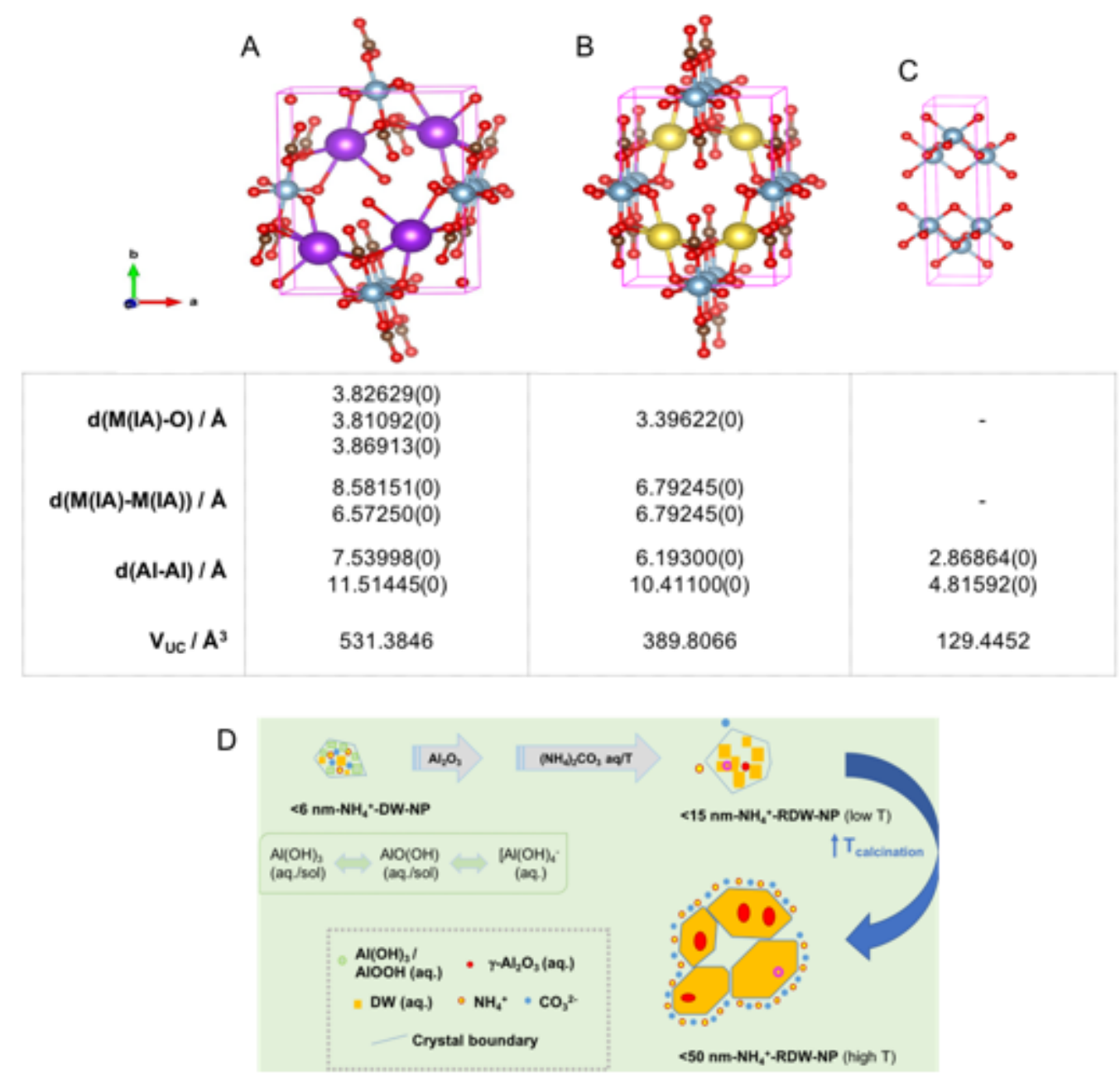

\section{Figure 3}

Predicted configuration for ammonium dawsonite solids. (A) Unit cell representation of natural Kdawsonite80 from AMS data 0007140 space group $\mathrm{Cmcm}$ as isomorphic of used NH4+-RDW-NP (H atoms not refined). (B) Unit cell representation of natural Na-dawsonite81 AMS data 0005083 space group Imam dawsonite. (C) Unit cell representation of boehmite AMS data 0014027 space group $\mathrm{Cmcm}$ ( 5 days at $473 \mathrm{~K}$ ).82 (D) Prediction for RDW and DW phases furnished by fast mixing conditions. Tentatively proposed morphology for ammonium dawsonite solids including one used as starting material $<15 \mathrm{~nm}$-RDW-NP (low T) for the synthesis of supported solids, deducted from experimental and reported data (see text). Blue external lines represent theoretical borders for the pure-nominal phase crystal to be formed.

\section{Supplementary Files}

This is a list of supplementary files associated with this preprint. Click to download.

- SISyntheticMaReSJansat.pdf

- GraphicalAbstract.docx 